\title{
Invited abstracts
}

\section{BIOTECHNOLOGY OF ENDOPHYTIC FUNGI: INORGANIC NANOMATERIALS AND DRUGS}

\author{
Absar Ahmad \\ Biochemical Sciences Division, National Chemical Laboratory, Pune 411008, MS, India. \\ e-mail: a.ahmad@ncl.res.in
}

One of the important challenges of considerable topical significance in nanotechnology is the development of eco-friendly experimental processes for the economical synthesis of nanomaterials in large quantities of variable size, shape, and chemical composition. While it is recognized that some of the most exquisite nanomaterials are made by biological systems (examples include silica in diatoms and magnetite in magnetotactic bacteria), the potential to exploit microorganisms in a creative manner in the laboratory for eco-friendly synthesis of nanomaterials is still largely under-exploited.

In this presentation, we describe our research into the use of plant microorganisms and plant extracts in the synthesis of metal, metal sulfide, and oxide nanoparticles. In a significant departure from bacteria-based methods for nanomaterial synthesis that have been investigated in some detail, we have shown that plant microorganisms such as fungi and actinomycetes when challenged with aqueous metal ions are capable of reducing the ions both intra- and extracellularly resulting in the formation of stable metal nanoparticles. The formation of metal nanoparticles occurs by an enzymatic process and thus, the fungus-based synthesis process is not limited to reduction reactions alone. The versatility of this approach is underlined by our findings that enzymes such as sulphite reductase, nitrate reductase, and hydrolyzing proteins are secreted by the fungi in response to metal stress thereby leading to the possibility of synthesis of quantum dots, metal nanoparticles, and nanooxides. The biosynthesis of nanooxides using fungi is exciting since the synthesis occurs at room temperature and thus could be of considerable commercial value.

Fungi enjoy a close symbiotic relationship with plants and hence, it is quite likely that plant extracts may also possess useful biomolecules that not only carry out the range of biotransformations listed above, but also control the shape of nanoparticles. We have studied a number of plant extracts for realizing metal nanoparticles and have observed that the Geranium and Lemongrass extracts result in shape modulated gold nanoparticles. In particular, the reaction of aqueous gold ions with Lemongrass extract resulted in the large-scale synthesis of gold nanotriangles with interesting near infrared absorption. Potential application of the gold nanotriangles and magnetite nanoparticles in hyperthermia of cancer cells and targeted drug delivery are being investigated.

We have also isolated, purified, and completely characterized a range of plant-based drugs such as Taxol, Vinblastine, Vincristine, Artemisinin, and Phyllanthin from endophytic fungi and recently initiated further important steps of functionalizing the nanoparticles synthesized by green chemistry approach for drug delivery application. 


\section{UTILIZATION OF 1,3-DIPOLAR CYCLOADDITION REACTION OF AZIDES TOWARD THE SYNTHESIS OF 5-MEMBERED HETEOCYCLIC COMPOUNDS}

\section{Sultan T. Abu-Orabi}

President, Yarmouk University, Irbid, Jordan.e-mail: abuorabi@excite.com; president@yu.edu.jo

1,3-Dipolar cycloaddition of organic azides to acetylenic and ethylenic compounds is the most important method for the synthesis of 1,2,3-triazole and triazoline derivatives, respectively. We have found that the reaction of substituted benzyl azides $\mathbf{1}$ and bis-(azidomethyl) benzenes $\mathbf{2}$ with dibenzoylacetylene $\mathbf{3}$ followed by treatment with hydrazine yields triazolopyridazines $\mathbf{4}$ and bis(triazolopyridazines) $\mathbf{5}$, respectively.

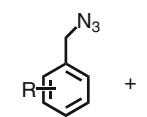

1<smiles>N#Cc1ccccc1N</smiles>

2<smiles>O=C([PH])C#CC(=O)c1ccccc1</smiles>

3
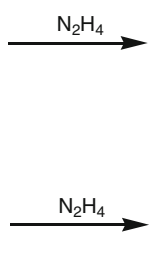

3<smiles>[R]c1ccc(Cn2nnc3c(-c4ccccc4)nnc(-c4ccccc4)c32)cc1</smiles>

4<smiles>c1ccc(Cn2nnc3c(-c4ccccc4)nnc(-c4ccccc4)c32)cc1</smiles>

We also synthesized a series of 4,5-bis[5-aryl-1,3,4-oxadiazol-2-yl]-1-substituted benzyl-1,2,3triazoles 8 upon dehydration of 4,5-bis [ $N$-aroyl- $N$-hydrazinocarbonyl]-1-substituted benzyl-1,2,3triazoles 7 (generated from substituted benzyl azides, dimethyl acetylenedicarboxylate, and hydrazine).

In a similar way, we prepared a series of 2-[1-benzyl-1,2,3-triazolo-4]-5-aryl-1,3,4-oxadiazoles 11 via dehydration of carbohydrazides $\mathbf{1 0}$.
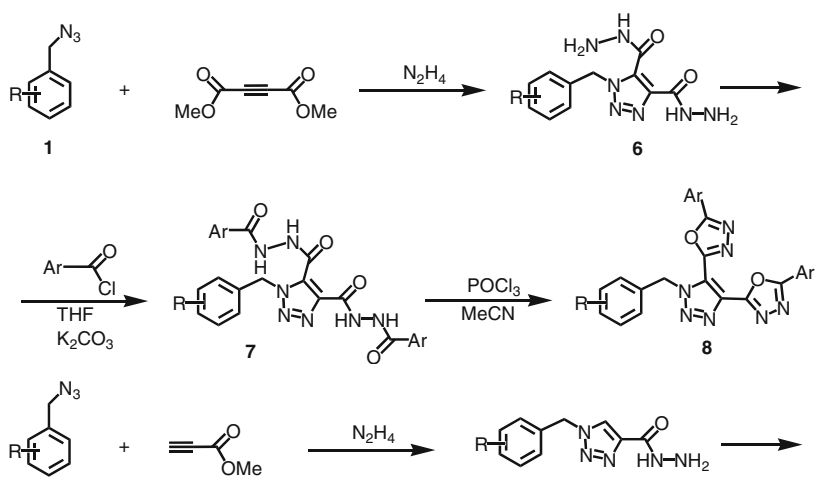

1

9

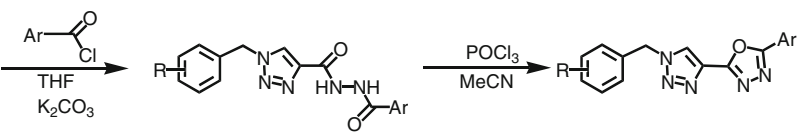

10

11

$\mathrm{R}=-\mathrm{Cl}, \mathrm{Br}, \mathrm{F}, \mathrm{CH}_{3}, \mathrm{OCH}_{3}, \mathrm{NO}_{2}$, Pentamethyl 
In the same manner, 4,5,4',5'-tetrakis[5-aryl-1,3,4-oxadiazol-2-yl]-1,1'-dibenzyl-1,2,3-triazoles $\mathbf{1 5}$ were synthesized. ${ }^{1-6}$

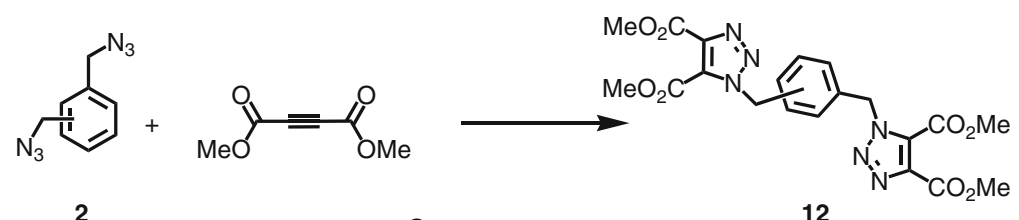

2
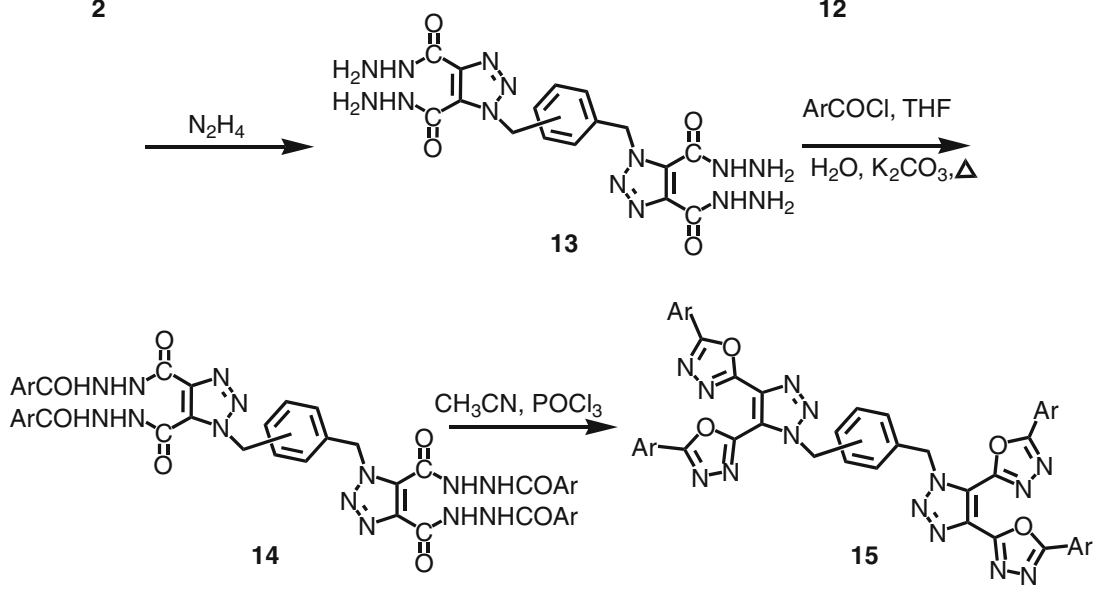

\section{References}

1. S. T. Abu-Orabi, R. Al-Hamdany, A. Atfah, A. A. S. Ali and K. Abu-Shandi, Asian J. Chem., 1999, 11,774 .

2. H. Tashtoush, S. T. Abu-Orabi, E. Ta'an and M. Al-Talib, Asian J. Chem., 1999, 11, 441.

3. M. Al-Talib, S. T. Abu-Orabi, S. Al-Majdalawi and H. Tashtoush, Ind. J. Heterocycl. Chem., 1999, 8, 183.

4. S. T. Abu-Orabi, Molecules, 2002, 7, 302.

5. S. T. Abu-Orabi, M. Saleh, I. Al-Momani, I. Jibril and Y. Yousef, Jordan J. Chem., 2006, 1,109.

6. S. T. Abu-Orabi, N. A. Abu-Naaj, S. Klaib, L. Al-Momani and I. Jibril, Jordan J. Chem., 2008, 3, 337.

\section{CLASSICAL AND NOVEL BIOLOGICS TARGETING CHRONIC INFLAMMATION}

\section{Ian Ahnfelt-Rønne}

Novo Nordisk A/S, Biopharmaceuticals Research Unit, 2760 Maalov, Denmark. e-mail:iar@novonordisk.com

The therapeutic potential of the classical biologics targeting chronic inflammation is based on their ability to block the function of TNF- $\alpha$, which is considered the master regulator of inflammatory responses in many organ systems. This class of compounds includes etanercept (Enbrel), an Fc fusion protein of TNF$\alpha$ receptor 2 that was first introduced in 1998; infliximab (Remicade), a chimeric IgG antibody against TNF- $\alpha$, launched for Crohn's disease in 1998 and rheumatoid arthritis (RA) in 1999; and adalimumab 
(Humira), a human anti-TNF- $\alpha$ antibody for RA and other chronic inflammatory conditions such as psoriasis and ankylosing spondylitis (2003). Other recently introduced anti-TNF- $\alpha$ biologics are Cimzia and Golimumab. This class of biologics is, with a few exceptions, broadly efficacious in treating a variety of autoimmune disorders such as RA and related arthritic conditions, Crohn's, and psoriasis. However, significant numbers of patients do not, or do only partially respond to treatment, and in others the effect wanes over time. Hence, novel biologics targeting alternative key regulators of the immune response have been introduced, and even more are in clinical and preclinical development. New targets include leukocyte surface proteins, complement, B lymphocytes, adhesion molecules, interferons, and a plethora of interleukins. The receptor of complement fragment C5a, C5aR, has been shown to be an important mediator of inflammatory arthritis in mice, in as much as a human antibody against C5aR was highly effective in reversing arthritis in a mouse model where the murine C5aR gene had been replaced with the human version. ${ }^{1}$ The IL-10 subfamily members, IL-20 and IL-24, and their receptors were expressed in synovium of RA and spondyloarthropathy pointing to an association with pathology in these conditions. ${ }^{2}$ Based on these observations, anti-C5aR and anti-IL-20 antibodies have entered into clinical development targeting chronic inflammation.

1. Lee et al., Nat. Biotechnol., 2006, 24, 1279.

2. Kragstrup et al., Cytokine, 2008, 41, 16; 1995, 34, 91.

\title{
DNA-TOPOISOMERASE INHIBITORY ACTIVITY OF SOME HETEROCYCLIC COMPOUNDS AND THEIR STRUCTURE-ACTIVITY RELATIONSHIPS
}

\author{
Esin Aki, Ismail Yalcin, Ilkay Yildiz, Ozlem Temiz-Arpaci, Kayhan Bolelli, Tugba Ertan-Bolelli \\ Pharmaceutical Chemistry Department, Faculty of Pharmacy, Ankara University, Tandogan 06100 \\ Ankara, Turkey.e-mail: esinaki@ankara.edu.tr
}

Eukaryotic topoisomerases is widely used in anticancer drug development that they are essential for several cellular processes such as replication, transcription, and chromosome condensation. Their antitumor activity is related to the formation of protein-concealed DNA strand breaks, resulting in the stabilization by the drug of an intermediary complex of the Topo II reaction. ${ }^{1}$

In this study, a new series of benzazoles, has been investigated for their inhibitory activity on eukaryotic DNA topoisomerase II in cell free system. ${ }^{2}$ The goal of this research was that predictions from the structure activity relationships of these tested compounds possibly will lead to design more active new DNA topoisomerase II inhibitors.

For the structure-activity relationship studies pharmacophore analysis was performed using Catalyst among a set of some Topo II inhibitor compounds which the general Formula given below.<smiles>[R2][Y]1:[Z](-c2ccc([R1])cc2[R4])nc2[Y]c([R1])ccc12</smiles>

1. D’Arpa, P., Liu, L. F., Biochim. Biophys. Acta, 1989, 989, 163.

2. Pinar, A., Yurdakul, P., Yildiz, I., Temiz-Arpaci, O., Acan, N. L., Aki-Sener, E., Yalcin, I., Biochim. Biophys. Res. Comm., 2004, 317, 670. 


\title{
NATURAL PRODUCT-INSPIRED SMALL MOLECULES AS MODULATORS OF CELL DEATH PATHWAYS INVOLVING BCL-2 Family
}

\author{
Prabhat Arya \\ Chemical Biology Program, Institute of Life Sciences (An Associate Institute of University of Hyderabad), \\ University of Hyderabad Campus, Gachibowli, Hyderabad 500046, India; Adjunct Professor, \\ Biochemistry, McGill University; Affiliate Investigator, Ottawa Hospital Research Institute; Member, \\ Ottawa Institute of Systems Biology.e-mail: prabhata@ilsresearch.org, \\ web: http://www.ilsresearch.org (see: chemical biology)
}

The research in our group aims at developing methods leading to high-throughput generation of natural product-inspired compounds with the goals of identifying chemical modulators of protein-protein interaction-based signaling pathways. Over the years, although the high-throughput synthetic approaches have been very successful in generating a large number of small molecules but in most cases, these compounds are simple in nature and thus lack the features that are commonly found in bioactive natural products (i.e., 3D architectures, rich in chiral display of dense functional groups, etc.). Through working in collaboration with David Andrews Team at McMaster University, several novel functional, chemical probes have been identified to date as chemical modulators of Bcl-2 protein family. The assays developed in his group are highly unique and allow us to investigate the modulation of protein-protein interactions and their functions in a membrane environment.

This talk will focus on the need to access novel natural product-inspired architectures in the postgenomic drug discovery arena.

\section{References}

1. P. Arya, R. Joseph, Z. Gan and B. Rakic. Exploring new chemical space by stereocontrolled diversity oriented synthesis. Chem. Biol., 2005, 12, 163-180.

2. A. Reayi and P. Arya. Natural product-like chemical space: search for chemical dissectors of macromolecular interactions. Curr. Opin. Chem. Biol., 2005, 9, 240-247 (Combinatorial chemistry theme issue-editors: P. Arya and H. J. Roth).

3. P. Arya and H. J. Roth. Combinatorial chemistry-editorial overview. Curr. Opin. Chem. Biol., 2005, 9, 229-231.

4. J. P. Nandy, M. Prakesch, S. Khadem, P. Thirupathi Reddy, U. Sharma and P. Arya. Advances in solution and solid phase synthesis toward the generation of natural product-like libraries. Chem. Rev. 2009, 109(5), 1999-2060.

\section{CADD AND SYNTHESIS IN THE DESIGN OF ANTI-MALARIAL AGENTS}

\author{
Prasad V. Bharatam
}

Department of Medicinal Chemistry, National Institute of Pharmaceutical Education and Research (NIPER), S.A.S. Nagar, Mohali 160 062, Punjab, India.e-mail: pvbharatam@niper.ac.in

A new class of chemical species with the general formula ${ }^{\oplus} \mathrm{N}(\leftarrow \mathrm{L})_{2}(\mathbf{I})$, with a formal $\mathrm{N}(+1)$ oxidation state has been identified. ${ }^{1}$ Several known molecules belong to this hitherto unrecognized class-well known example is the anti-malarial prodrug proguanil hydrochloride. Electronic structure analysis indicates that this class of compounds possesses two lone pairs of electrons on a nitrogen atom with a formal positive charge. The central core of this class of molecules is isoelectronic to the central core of carbodicarbenes $\mathrm{C}(\leftarrow \mathrm{NHC})_{2}$ (II), thus, offers ample opportunities for basic and applied research in chemistry. This electronic environment in biguanide analogs, offers increased dynamism to the system through reduced $\mathrm{C}=\mathrm{N}$ rotational barriers and easy $\mathrm{N}$-inversion processes. Several clues have been obtained from the above analysis, which helped in the design and synthesis of anti-malarial guanyl 
thiourea derivatives (IV). QSAR, Pharmacophore mapping, molecular docking, and virtual screening analyses have been carried out to design anti-malarial agents against resistant strains of Plasmodium. ${ }^{2-6}$<smiles>[R]C[C@H](C=C1NC=CN1)N1C=CNC1[R]</smiles><smiles>[R]C([R])=[N+]([O-])C([R])[R]</smiles>

$\oplus$<smiles>N[14C](N)N[14C@@H](N)[15NH]</smiles>

\section{References}

1. Patel, D. S. and Bharatam, P. V., Chem. Commun., 2009, 1064.

2. Kessar, S. V. and Bharatam, P. V., Angew. Chem. Int. Ed. Engl., 2008, 47, 4703.

3. Kessar, S. V., Venugopalan, P., and Bharatam, P. V. J. Am. Chem. Soc., 2007, 129, 4506.

4. Bharatam, P. V., Patel, D. S., and Iqbal, P. J. Med. Chem., 2005, 48, 7615.

5. Khanna, S., Sobhia, M. E., and Bharatam, P. V., J. Med. Chem., 2005, 48, 3015.

6. Bharatam, P. V., Iqbal, P., Malde, A., and Tiwari, R., J. Phys. Chem. A., 2004, 108, 10509.

\section{A PRACTICAL APPROACH FOR DEVELOPING NEXT GENERATION SAFE AND EFFECTIVE DRUGS}

\section{Laxminarayan Bhat}

Reviva Pharmaceuticals, Inc. 5941 Optical Court, San Jose, CA 95138, USA. e-mail: LBhat@Revivapharma.com

Drug discovery and development is a complex and highly challenging process. Despite significant advances in biomedical research over the last three to four decades, the attrition rates of new chemical entities (NCEs) in preclinical and clinical development are staggeringly high. ${ }^{1}$ In addition, several approved drugs have been withdrawn from the market in recent years due to their serious adverse drug reactions $^{2,3}$ (ADRs) leading to number of reported deaths. Therefore, in addition to finding the right strategy and target the ability to assess the efficacy and safety profile of NCEs early in the development process holds tremendous value for the pharmaceutical industry.

Reviva Pharmaceuticals, Inc., is focused on developing novel Redesigner Drugs ${ }^{\mathrm{TM}}$ for CNS, metabolic, cardiovascular, and inflammatory indications by redesigning the approved existing drugs which are known to cause ADRs. Reviva's innovative drug development approach has several advantages over the conventional de novo approach such as the ability to assess the efficacy and safety profile of NCEs throughout the development process, reduced cost and time to market. The company believes that the redesigned drugs will be safe and efficacious than the existing drugs. Reviva's drug development approach including the preclinical efficacy and safety profiles of the redesigned drugs for obesity (RP1000) and schizophrenia/bipolar (RP5000) indications will be presented.

\section{References}

1. Shah, S., Drug Discov. Today 2009, 14, 1006.

2. Goldstein, D. B., N. Engl. J. Med. 2003, 348, 553.

3. Weinshillboum, R., N. Engl. J. Med. 2003, 348, 529. 


\section{COPPER-CATALYZED REACTIONS FOR THE SYNTHESIS OF BIOLOGICALLY ACTIVE HETEROCYCLES}

\section{Uwe Beifuss}

Bioorganic Chemistry, Department of Chemistry, University of Hohenheim, Garbenstr. 30, 70599 Stuttgart, Germany. Fax: +49-711-45922951; email: ubeifuss@uni-hohenheim.de

In the light of the growing importance of enzymatically catalyzed reactions, it is surprising that the potential of enzymatically initiated domino reactions has so far hardly been exploited. In this context, enzymes that are capable of conducting an oxidation triggering a domino reaction are very promising. This is why laccases have a very high potential for the development of oxidative domino processes. Laccases (E.C. 1.10.3.2) are multicopper oxidases that are capable of oxidizing a wide range of substrates while concomitantly reducing $\mathrm{O}_{2}$. They contain a T1, a T2, and a T3 Cu center. T2 and T3 form a trinuclear $\mathrm{Cu}$ cluster. The oxidation of the substrate occurs at the $\mathrm{T} 1 \mathrm{Cu}$ center. The electrons are transferred to the trinuclear $\mathrm{Cu}$ cluster where $\mathrm{O}_{2}$ is reduced to $\mathrm{H}_{2} \mathrm{O}$.<smiles>[R]C(=O)/C=C(/[R])O</smiles><smiles>Oc1cccc(O)c1</smiles><smiles>CCCCCCCCCO</smiles>

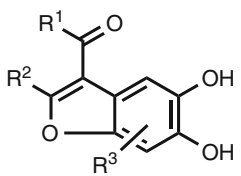

Here we report on the efficient laccase initiated domino reactions of a multitude of 1,3-dicarbonyls with catechols into heterocycles with a benzofuran core employing air as an oxidant. ${ }^{1-3}$ We also highlight on the combined action of a tyrosinase and a laccase which allows the use of phenol instead of catechols to produce the respective $O$-heterocycles. ${ }^{4}$

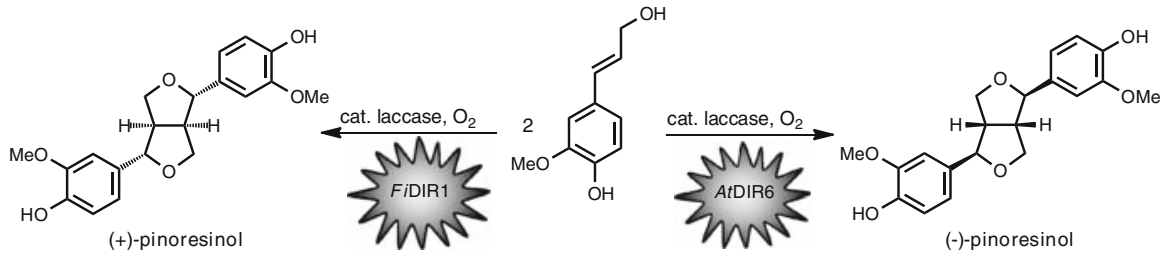

We also present the cloning, expression, purification, and functional characterization of a dirigent protein (AtDIR6) from Arabidopsis thaliana, which mediates the laccase-catalyzed enantioselective oxidative phenol coupling of coniferyl alcohol to (-)-pinoresinol. ${ }^{5}$ We further show that the enantioselectivity of AtDIR6 is opposed to that of the known dirigent protein FiDIR1 from Forsythia.

A third project addresses the use of $\mathrm{Cu}(\mathrm{I})$-catalyzed sequential processes for the synthesis of heterocycles which is exemplified by the reaction of 2-bromobenzyl bromide with $\beta$-ketoesters to yield $4 H$-chromenes in high yields. ${ }^{6}$

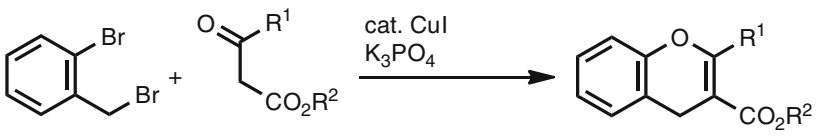

\section{References}

1. H. Leutbecher, J. Conrad, I. Klaiber, U. Beifuss, Synlett 2005, 3126.

2. S. Hajdok, H. Leutbecher, G. Greiner, J. Conrad, U. Beifuss, Tetrahedron Lett. 2007, 48, 5073.

3. S. Hajdok, J. Conrad, H. Leutbecher, S. Strobel, T. Schleid, U. Beifuss, J. Org. Chem. 2009, 74, 7230 . 
4. H. Leutbecher, S. Hajdok, C. Braunberger, M. Neumann, S. Mika, J. Conrad, U. Beifuss, Green Chem. 2009, 11, 676.

5. B. Pickel, M.-A. Constantin, J. Pfannstiel, J. Conrad, U. Beifuss, A. Schaller, Angew. Chem. Int. Ed., 2007, 46, 5916-5920.

6. C. C. Malakar, U. Beifuss, unpublished results.

\title{
THE FIGHT AGAINST AIDS: THE “OLD” REVERSE TRANSCRIPTASE (RT) AND THE “NEW" DDX3
}

\author{
Maurizio Botta \\ Dipartimento Farmaco Chimico Tecnologico, University of Siena, Via Aldo Moro, 53100 Siena, Italy. \\ e-mail: botta@unisi.it
}

A multitarget approach to fight the HIV-1 virus is presented. It is focused on the inhibition of HIV-1 reverse transcriptase (RT) and of DDX3, a DEAD box ATP-dependent RNA helicase. RT is a multifunctional enzyme, consisting of a p66 and a p51 subunits, responsible for the conversion of the single-stranded RNA viral genome into a double-stranded DNA. Lacking a biological counterpart in the eukaryotic systems, RT is an attractive target for development of selective inhibitors. Among nonnucleoside RT inhibitors (NNRTI), dihydro-alkoxy-benzyl-oxopyrimidines (DABOs) are an interesting class of compounds active at nanomolar concentration, that were first discovered in 1992 and further developed during the following years into $S$-DABO and related analogues. Several innovative molecular modeling and synthetic techniques were successfully applied to improve the activity of a class $S$-DABOs toward wt RT and some clinically relevant mutants and to the identification of the first RT dimerization inhibitor. Furthermore, a combinatorial approach led to the identification of a new class of compounds (namely 6-vinylpyrimidines) endowed with an unprecedented mechanism of action. These compounds are the first NNRTIs competing with the nucleotide substrate. An enzymological and computational study, followed by the crystallization of the complex between RT and a 6-vinylpyrimidine, has been conducted to elucidate their unique mechanism of action. ${ }^{1-3}$

Compounds currently used for the treatment of HIV-1 infections are targeted to viral proteins. However, the high intrinsic mutation and replication rates of HIV-1 led to the emergence of drug-resistant strains with a consequent therapeutic failure. On this basis, cellular cofactors represent attractive new targets for HIV-1 chemotherapy, since targeting a cellular factor that is required for viral replication should help to overcome the problem of viral resistance. In this context, a structure-based pharmacophoric model based on the X-ray crystallographic structure of human helicase DDX3 was inserted in a virtual screening approach leading to the discovery of the first small molecule inhibiting HIV-1 replication by targeting DDX3. It represents a hit compound for a completely new class of antiviral agents. ${ }^{4}$

\section{References}

1. Radi, M., Maga, G., Alongi, M., Angeli, L., Samuele, A., Zanoli, S., Bellucci, L., Tafi, A., Casaluce, G., Giorgi, G., Armand-Ugon, M., Gonzalez, E., Esté, J. A., Baltzinger, M., Bec, G., Dumas, P., Ennifar, E., Botta, M., J. Med. Chem. 2009, 52, 840-851.

2. Maga, G., Radi, M., Zanoli, S., Manetti, F., Cancio, Hübscher, R. U., Spadari, S., Falciani, C., Terrazas, M., Vilarrasa, J., Botta, M. Angew. Chem. Int. Ed. 2007, 46, 1810-1813.

3. Grohmann, D., Corradi, V., Elbasyouny, M., Baude, A., Horenkamp, F., Laufer, S. D., Manetti, F., Botta, M., Restle, T., Chembiochem 2008, 9, 916-922.

4. Maga, G., Falchi, F., Garbelli, A., Belfiore, A., Witvrouw, M., Manetti, F., Botta, M., J. Med. Chem. 2008, 51, 6635-6638. 


\title{
NOVEL QUANTITATIVE STRUCTURE-ACTIVITY ANALYSES OF PROTEIN INHIBITORS USING FULL AB INITIO MOLECULAR ORBITAL CALCULATIONS ON THEIR COMPLEX STRUCTURES WITH PROTEIN
}

\author{
Tatsusada Yoshida, Yohei Munei, Hiroshi Chuman
}

Institute of Health Biosciences, University of Tokushima, 1-78, Shomachi, Tokushima, 770-8505, Japan. e-mail: hchuman@ph.tokushima-u.ac.jp

A novel QSAR procedure has been desired to understand quantitatively the ligand-protein interaction at atomic and electronic levels. In this paper, we demonstrate the performance of our recently proposed novel QSAR procedure using ab initio fragment molecular orbital (FMO) calculations on ligand-protein complex structures. ${ }^{1,2}$

\section{Cyclic urea type inhibitors (CUIs) of HIV-1 protease (HIV-1 PR)}

QSAR analyses on a series of CUIs including DMP323 were performed using molecular dynamics (MD) and FMO (HF/6-31G and MP2/6-31G) calculations on the whole complex structure of HIV-1 PR with each CUI. Two descriptors showing correlation with the inhibitory potency $\left(\log \left(1 / K_{\mathrm{i}}\right)\right)$ were the total electronic interaction energy and the change in the accessible surface area $(\triangle A S A)$ on the complex formation. The Inter-Fragment Interaction Energy (IFIE) term is one of the most advantageous outcomes directly obtained from the FMO theory. Figure 1 shows IFIE values of DMP323 with all the amino acid residue fragments $(99 \times 2)$ in HIV-1 PR. The IFIE analysis revealed that the major contribution to the variations in the total electronic interaction energy comes from amino acid residues surrounding a CUI, especially from Asp30. The inhibitory potency is nicely expressed using $\triangle A S A$ and [IFIE(30) + IFIE(31)], which represents the electronic interaction energy of Asp30 (30') with a CUI.

$$
\log \left(1 / K_{\mathrm{i}}\right)=-0.0306[\operatorname{IFIE}(30)+\operatorname{IFIE}(31)]+9.55 \times 10^{-3} \Delta A S A+19.1
$$

$n=13, r=0.910, s=0.485, F=24.2(\mathrm{MP} 2 / 6-31 \mathrm{G})$

\section{Benzenesulfonamides (BSAs) with carbonic anhydrase (CA)}

QSAR analyses on the binding potency $\left(\log K_{\mathrm{b}}\right)$ of substituted BSAs with bovine CA were performed according to the procedure similar to that used in 1. The modified IFIE analysis quantitatively revealed that the binding potency is governed by interactions with amino acid residues in the active site, as shown in Fig. 2.

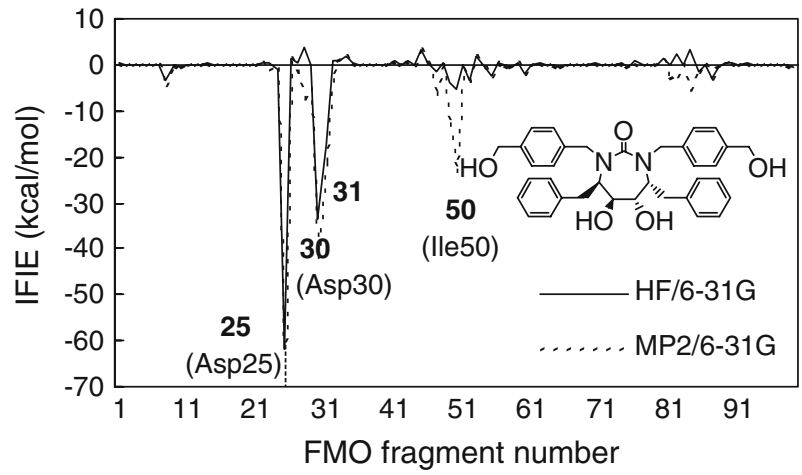

Fig. 1 IFIE map of CUI (DMP323) with HIV-1 PR 
Fig. 2 BSA bound in the active site of CA

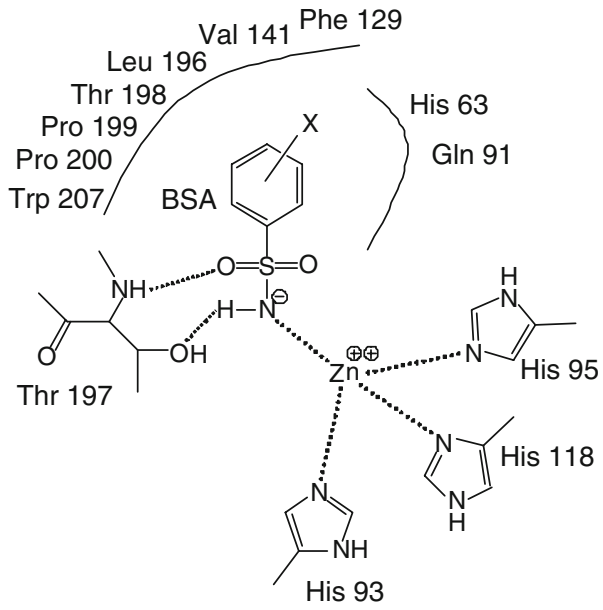

$\log K_{\mathrm{b}}=-0.245 \Sigma_{\text {in the active site }}$ IFIE (i) -23.9 .

$n=16, r=0.983, s=0.211, F=392(\mathrm{HF} / 6-31 \mathrm{G}) ; n=16, r=0.983, s=0.211, F=392(\mathrm{HF} / 6-$ $31 \mathrm{G})$.

$\mathrm{Zn}$ block $\left(\mathrm{Zn}^{2+}\right.$, His93, His95, and His118) gives the lowest interaction energy and the largest variance of interaction energy with $\mathrm{CA}$ through their coordination interaction, and govern the binding potency dominantly.

The two examples are reasonably considered to show that the novel descriptors obtained from the MD-FMO procedure are able to represent physicochemical features of the ligand-protein interaction clearly. It is noteworthy that the IFIE term attributable to the interaction energy of a ligand with a component amino acid residue in the protein, instead of the classical QSAR parameters attributable to a ligand, is able to work as QSAR descriptors in analyzing the complex formation. The results also provide an answer as to why the classical QSAR descriptors such as Hammett $\sigma$ are frequently significant in the enzymatic QSAR equations.

\section{References}

1. Yoshida, T., Fujita, T., and Chuman, H., Curr. Comput. Aided Drug Design, 2009, 5, 38.

2. Yoshida, T., Yamagishi, K., and Chuman, H., QSAR Comb. Sci., 2008, 27, 694.

\section{PYRROLO-QUINOLINONES WITH POTENT PHOTOCHEMIOTHERAPEUTIC ACTIVITY WITHOUT DNA DAMAGE}

\section{Girolamo Cirrincione}

University of Palermo, Dipartimento Farmacochimico Tossicologico e Biologico, Via Archirafi 32, 90123 Palermo, Italy.e-mail: gcirrinc@unipa.it

PUVA therapy combines the use of Psoralen 1 with UVA radiation for the treatment of dermatological diseases with hyperproliferative and/or autoimmune character, such as psoriasis, vitiligo and cutaneous T-cell lymphoma. ${ }^{1}$ 


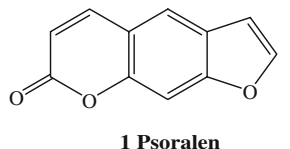

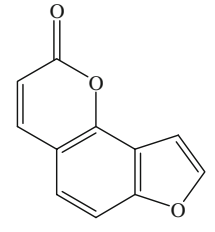

2 Angelicin<smiles></smiles>

$3 \mathrm{Y}=\mathrm{C}-\mathrm{R}, \mathrm{W}=\mathrm{N}-\mathrm{R}, \mathrm{Q}=\mathrm{C}-\mathrm{Me}$ $4 \mathrm{Y}=\mathrm{W}=\mathrm{C}-\mathrm{R}, \mathrm{Q}=\mathrm{N}-\mathrm{R}$ $5 \mathrm{Y}=\mathrm{N}-\mathrm{R}, \mathrm{Q}=\mathrm{C}-\mathrm{R}, \mathrm{W}=\mathrm{C}-\mathrm{H}$

The introduction of extracorporeal photochemotherapy ${ }^{2}$ (ECP) represents an evolution of the PUVA therapy for the treatment of cutaneous T-cell lymphoma (CTCL), T-cell mediated autoimmune diseases. ${ }^{3}$ Unfortunately, the antiproliferative effect of this class of linear furocoumarins, is associated to undesiderable short- and long-term side effects. These latter, such as genotoxicity and mutagenicity, are caused by interstrand crosslinks (ISC). ${ }^{4}$ Angelicin 2, is an angular furocoumarin which, for its molecular geometry, cannot produce ISC resulting less toxic than its linear congener. In this context several angelicin isosters have been studied. ${ }^{5}$ We have recently reported the synthesis of pyrroloquinolinones of type 3-5 to verify the influence of the condensation of the pyrrole ring to the quinoline moiety. Such ring systems showed potent photoantiproliferative activity being in some cases higher than 8-MOP $\left(\mathrm{GI}_{50}{ }_{0.4}\right.$ $16.4 \mu \mathrm{M}, 0.4-15.0 \mu \mathrm{M}$, and 0.5-9.0 $\mu \mathrm{M}$, respectively). ${ }^{6}$ Experiments performed to better understand the biological targets, demonstrated that compound 3-5 do not interact with DNA, but mithocondria and lysosomes may be involved in the photoinduced apoptotic cell death. The most relevant feature is that pyrrolo[3,2- $h]$ quinolinones 5 exhert their activity without inducing DNA photodamage.

\title{
References
}

1. Dall'Acqua, F., et al. Eds. CRC Press, Boca Raton, USA, 2004, pp. 1-17.

2. Edelson, R., et. al. N. Engl. J. Med., 1987, 316, 297-303.

3. Rook, A. A., et al. NY Acad. Sci. 1991, 636, 209-216; Gollnick, H. P. et al. J. Acad. Dermatol. 1993, $28,122-124$.

4. Kirland, D. J., et al. Mutat. Res. 1983, 116, 73-82; Venturini, V., et al. Mutat. Res. 1981, 88, 17-22.

5. Rodighiero, P., et al. J. Med. Chem. 1996, 39, 1293-1302; Jacobs, A. E., et al. J. Med. Chem. 1995, 38, 869-874.

6. Barraja, P., et al. Bioorg. Med. Chem., 2006, 14, 8712-8728.

\section{BIOACTIVE NATURAL PRODUCTS: NATURE'S GIFT TO SCIENCE}

\author{
David Yu-Kai Chen
}

Chemical Synthesis Laboratory (CSL) @ Biopolis, Institute of Chemical and Engineering Sciences (ICES), Agency for Science, Technology and Research (A*Star), 11 Biopolis Way, The Helios Block \#0308, Singapore 138667, Singapore.e-mail: david_chen@ices.a-star.edu.sg

The total synthesis of natural products has served admirably as the cradle for the evolution of chemical sciences, and nurtured the discovery of novel synthetic technologies and strategies. In conjunction with the biological activities harnessed by the natural substances, accessing natural and designed compounds by chemical means also has a cemented position in bridging biology and medicine. Chemical Synthesis Laboratory@Biopolis has been actively pursuing number of architecturally complex natural products exhibiting promising therapeutic potentials, and served a crucial role in advancing our understanding in chemistry and chemical biology. In this talk, recently accomplished total syntheses of bioactive natural products will be described. Emphasis will be placed on the strategic design and recognizing the unique reactivity embedded within the molecular scaffold, and opportunities in the application of synthetic technologies in chemical-biology investigations. 


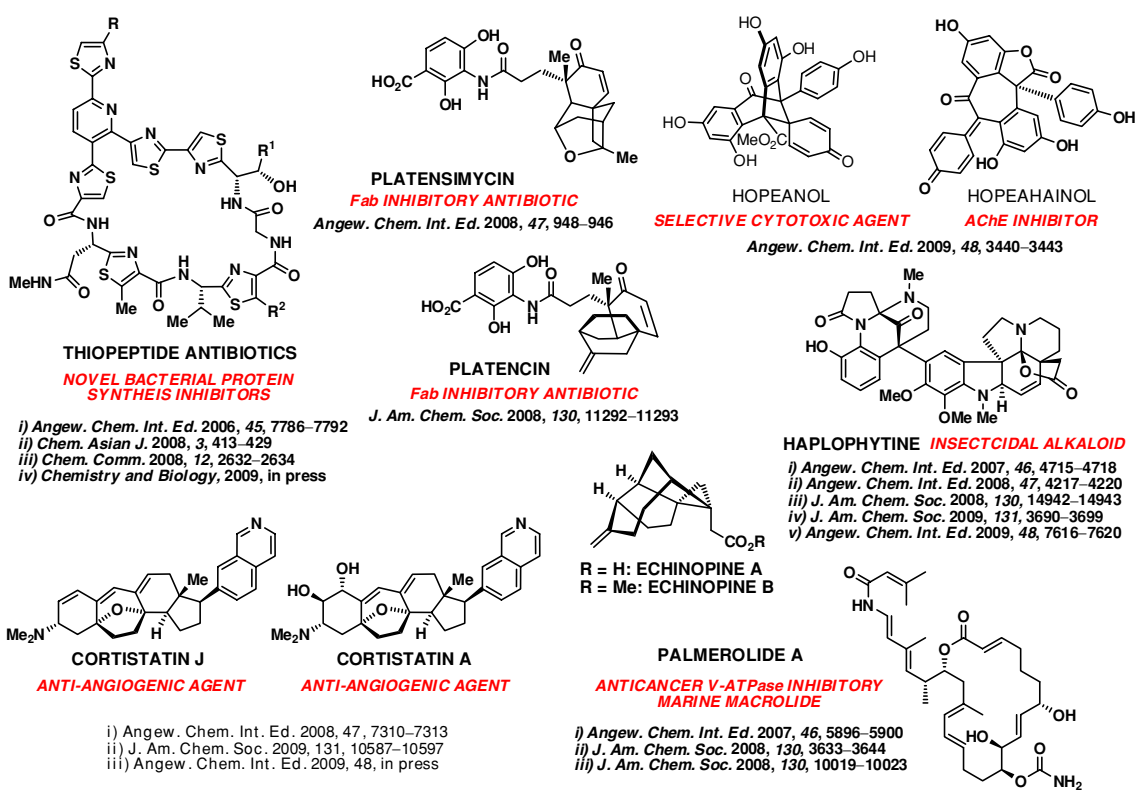

\section{References}

1. Total synthesis of antibiotics GE2270A and GE2270T. Angew. Chem. Int. Ed. 2006, 45, 7786-7792.

2. A chiral pool based synthesis of platensimycin. Angew. Chem. Int. Ed. 2008, 47, 944-946.

3. Chemical synthesis and biological evaluation of the palmerolide A analogs. J. Am. Chem. Soc. 2008, 130, 10019-10023.

4. An expedient asymmetric synthesis of platencin. J. Am. Chem. Soc. 2008, 130, 11292-11293.

5. Total synthesis of hopeahainol A and hopeanol. Angew. Chem. Int. Ed. 2009, 48, 3440-3443.

6. Total synthesis and biological evaluation of cortistatins $\mathrm{A}$ and $\mathrm{J}$ and analogues thereof. J. Am. Chem. Soc. 2009, 131, 10587-10597.

7. Identification of distinct thiopeptide-antibiotic precursor lead compounds using translation machinery assays. Chem. Biol. 2009, 16, in press.

8. Cortistatin A is a high affinity ligand of protein kinases ROCK, CDK8, and CDK11. Angew. Chem. Int. $E d . \mathbf{2 0 0 9}, 48$, in press.

9. Total synthesis of (+)-haplophytine. Angew. Chem. Int. Ed. 2009, 48, 7616-7620.

\section{TOWARDS ACCELERATED ANTI-CANCER DRUG DISCOVERY: INTEGRATION OF CHEMOINFORMATICS, CELL-BASED SCREENING, AND GRID COMPUTING}

György Dormán, ${ }^{1}$ Sándor Cseh, ${ }^{1}$ István Bágyi, ${ }^{1}$ Péter Kacsuk, ${ }^{2}$ József Kovács, ${ }^{2}$ Angelo Carotti, ${ }^{6}$ Orazio Nicolotti ${ }^{6}$ Simona Distinto, ${ }^{3}$ Gerhard Volber, ${ }^{3}$ Amiram Goldblum, ${ }^{4}$ David Marcus, ${ }^{4}$ Alfons Nonell-Canals, ${ }^{5}$ Jordi Mestres, ${ }^{5}$ Andre Lomaka, ${ }^{7}$ Miklós J. Szabó, ${ }^{8}$ Béla Bertók ${ }^{8}$

${ }^{1}$ Targetex, Kápolna köz 4/a Dunakeszi 2120, Hungary; ${ }^{2}$ Computer and Automation Research Institute, Victor Hugo u. 18-22, Budapest, 1132, Hungary; ${ }^{3}$ Inte:Ligand GmbH, Clemens Maria Hofbauer-Gasse 6, 2344 Maria Enzersdorf, Austria; ${ }^{4}$ Hebrew University of Jerusalem, Jerusalem 91120, Israel; ${ }^{5}$ University Pompeu Fabra; Barcelona Biomedical Research Park C/Doctor Aiguader, 88, 08003 Barcelona, Spain; 
${ }^{6}$ University of Bari, Via E Orabona 4, 70125 Bari, Italy; ${ }^{7}$ University of Tallinn, Akadeemia tee 15, 12618 Tallinn, Estonia, ${ }^{8}$ AMRI Hungary, Záhony u. 7, Budapest, 1031, Hungary.e-mail: dorman@targetex.com

CancerGrid, a 3-year European Research Project (www.cancergrid.eu) aims to integrate computer technologies, chemistry and biology to facilitate the discovery of potential anti-cancer agents. The core of this approach is comparative cell-based screening (applying cancer and reference cell lines), which not only validates the hits (selectively cytotoxic compounds) as potential anti-cancer agents, but also fits to the latest concept of polypharmacology. In the first phase of the project, 30,520 small molecules were selected by various state-of-the-art computational methods from the AMRI library of 200,000 compounds and University of Bari internal collection of 1,500 compounds. Single point high-throughput screening of the selected compounds was performed on HCT116 colon cancer cells at $50 \mu \mathrm{M}$ concentration. From the resulting cytotoxic compounds ( $<20 \%$ viability), a diverse sublibrary was selected for $\mathrm{IC}_{50}$ determination on HCT116 and on the reference MRC-5 cell-line. In the next phase, a QSAR model was attempted to build based on the screening results for predicting disease-related cytotoxicity utilizing a purpose-built grid computing system. Iterative stochastic elimination (ISE) indexing method was extended to calculate a Cyto-Toxicity Index (CTI) from the hit compounds, which can prioritize potential cytotoxic compounds in large databases. Since it is assumed that related chemical structures act through similar targets and signaling pathways, the model building was supported with an in silico target annotation method. The final stage of the project is in silico design of anti-cancer focused libraries and its experimental validation. In the lecture, the CancerGrid system will be described together with the results and the experience gained during the development of the grid infrastructure and the project execution.

\title{
FROM 2D TO 4D QSAR MODELING: MODEL BUILDING AND VALIDATION ON HIV-INTEGRASE INHIBITORS
}

\author{
Márcia M. C. Ferreira \\ Institute of Chemistry, University of Campinas, 13083-740 Campinas, SP, Brazil. \\ e-mail: marcia@iqm.unicamp.br
}

Quantitative structure-activity relationships (QSARs) is now-a-days a very heterogeneous area of theoretical medicinal chemistry, mainly because of several ways to calculate, use and interpret molecular descriptors: ranging from so-called 2D or classical, over 3D, 4D, and higher dimensional, to hybrid (2D/ 3D, 2D/4D etc.) QSARs. Our group has experience with a variety of 2D, 3D, and 4D QSARs, resulting in a recently launched $L Q T A-Q S A R,{ }^{1}$ a free, $4 \mathrm{D}-\mathrm{QSAR}$ software. It is based on GROMACS molecular simulations, use of conformational ensemble profile for each compound coupled with the calculation of the 3D descriptors for diverse probes (LQTAgrid module). QSAR Modeling is the other free, home-made software, designed for chemometrically correct model building using PLS, and validation independently on the type of QSAR descriptors used. It takes into account basic statistical issues that are frequently not well or completely carried out in QSAR publications: transparent and effective variable pre-selection and selection with the Ordered Predictors Selection (OPS) algorithm ${ }^{2}$ also recently published by our group; outlier detection; leave-many-out crossvalidation; Y-randomization; multicollinearity (especially the sign change problem) and consistent model interpretation. This lecture will illustrate all these aspects for 2D, 3D, 4D, and mixed QSAR models for $\beta$-diketone inhibitors of the HIV-1 integrase, and discuss advantages and disadvantages of particular models.

\section{References}

1. Martins, J. P., Barbosa, E. G., Pasqualoto, K. F. M., and Ferreira, M. M. C., Chem. Inf. Mod., 2009, 49, 1428.

2. Teófilo, R. F., Martins, J. P, and Ferreira, M. M. C., J. Chemometr., 2009, 23, 32. 


\title{
RATIONAL DESIGN AND DEVELOPMENT OF A BROAD SPECTRUM ANTIVIRAL DRUG: AN INTERFERON MIMETIC
}

\author{
Eleanor N. Fish, Lakshmi P. Kotra \\ Toronto General Research Inst., University Health Network \& University of Toronto, 67 College Street, \\ Rm. 424, Toronto, Ontario M5G 2M1, Canada.e-mail: en.fish@utoronto.ca
}

IFNs- $\alpha / \beta$ function as the first line of defense against viral infections by modulating cell growth, establishing an antiviral state and influencing the activation of various immune cells. In recent years, emerging viral infections have become more frequent, creating an urgent need for effective therapeutic solutions. Although vaccination against a specific virus is the best preventative approach, the time to develop a targeted vaccine precludes its immediate use during an outbreak of a newly emerging virus. Antiviral drugs can be deployed quickly and therefore represent the first line of defense during an initial outbreak. Antiviral drug development to date has focused on each drug targeting a specific virus. Antiviral drugs that are pathogen-specific have a role, yet concerns relating to the development of drug resistance necessitates consideration of complementary antiviral strategies. An alternative strategy is to focus on the host immune response to virus infection and identify specific factors that are rapidly activated in response to many different virus infections. Interferons (IFN) are critical for host resistance to viral infections, mediating direct antiviral responses in target cells, while inducing both innate and adaptive immune responses in the infected host.

Hypothesis: Development of broad spectrum antivirals that are host-specific and not pathogen-specific provides for widespread protection against emerging and re-emerging viruses and avoids drug resistance. Approach: Enhance the host innate immune response by manipulating the IFN response. That is, develop next generation IFN- $\alpha$ s, IFN mimetics, as small molecule drugs.

Motivation: Historically, antiviral strategies involving vaccinations and antiviral have been pathogen focused and some have serious downsides including increasing numbers of severe and drug-resistant cases of disease, insufficient time to develop and manufacture targeted vaccines, limited quantities of supplies, unpredictable efficacy.

Utilizing a model we have developed for the complex of IFN- $\alpha$ with the IFN receptor, IFNAR, comprised of IFNAR1 and IFNAR2 subunits, we performed an in silico screen of the ZINC6 molecular database for compounds that mimic IFN- $\alpha$ in the context of its interactions with IFNAR1 and IFNAR2. A set of 35 compounds with suitable characteristics were identified. Two compounds from the set of 35 were selected, based on their chemical nature and their potential interaction with the receptor sites. Two focused libraries of compounds, for a total of 50 compounds, are currently being evaluated for IFN agonist bioactivity. Specifically, these compounds are evaluated for biopotency against a panel of viruses in vitro and in vivo.

\section{MODELING CHEMICAL REACTIONS IN DRUG DESIGN AND CHEMICAL RISK ASSESSMENT}

\author{
Johann Gasteiger \\ Computer-Chemie-Centrum, Universität Erlangen-Nürnberg, 91052 Erlangen, Germany; Molecular \\ Networks GmbH, Henkestr. 91, 91052 Erlangen, Germany. web: http://www.molecular-networks.com
}

Chemical reactions play a major role at many steps of the drug design process. A better understanding and modelling of chemical reactions could greatly increase the efficiency in developing a new drug.

In target identification, an understanding of enzyme reactions is needed.

In lead discovery and lead optimization, an estimate of synthetic accessibility is desired, syntheses have to be designed, and the synthesis of a library asks for knowledge on the scope and limitations of a reaction type. Furthermore, knowledge on the stability of the compounds of a library is necessary.

The estimation of $A D M E-T o x$ properties has to model the metabolism of drugs and has to predict $\mathrm{pKa}$ values. Furthermore, many toxic modes of action are the result of chemical reactions.

Legislature has been introduced in Europe (REACH-registration, evaluation and accreditation of chemicals) that requires proof of the safety of chemicals that are in industrial use. As the testing of 
chemicals is time-consuming and expensive, computer methods for chemical risk assessment are being developed in order to rank the chemicals for testing. This assessment of chemicals again asks for the prediction of metabolism and of environmental degradation. Examples for modelling these various types of chemical reactions will be given. ${ }^{1}$

\title{
Reference
}

1. J. Gasteiger, J. Comput. Aided Mol. Des., 2007, 21, 33-52.

\section{NOVEL THIAZOLYL THIAZOLYDIN-4-ONE DERIVATIVES AS HIV-1 REVERSE TRANSCRIPTASE INHIBITORS. POTENTIAL NOVEL DRUGS FOR THE TREATMENT OF AIDS}

\author{
Geronikaki Athina, ${ }^{1}$ Pitta Eleni, ${ }^{1}$ Surmava Sofiko, ${ }^{2}$ Eleftheriou Phaedra ${ }^{2}$ \\ ${ }^{1}$ Aristotle University if Thessaloniki, Greece; ${ }^{2}$ Alexandrion Technological Educational Institute of \\ Thessaloniki, Greece
}

Reverse transcriptase (RT) inhibitors are among the drugs mostly used for the treatment of human immunodeficiency virus type 1 (HIV-1) infection. Although, many compounds are licensed and already used as anti-HIV drugs, research on development of novel inhibitors continues since drug-resistant strains appear inevitably because of prolonged therapy of the patients.

Both nucleoside/nucleotide (NRTI) and non-nucleoside analogues (NNRTI) have been used as RTinhibitors for decades with NNRTIs having the benefit of exhibiting less undesired side effects.

In the present study, thirteen $N$-\{(MeO/EtO-benzo $)[\mathrm{d}]$ thiazolyl $\}-(2-(\mathrm{Cl} / \mathrm{F}$-phenyl $))$-thiazolydin-4-one derivatives were synthesised and tested as HIV-1 RT inhibitors.

Evaluation of their inhibitory action was made by a colorimetric photometric enzyme immunoassay method.

According to the results, some of the tested compounds had $\mathrm{IC}_{50}$ values at the micromolar or submicromolar range. Remarks on the effect of the kind and position of substituents were done.

\section{References}

1. Falco, V., Rodriguez, D., Ribera, E., Martinez, E., Miro, J. M., Domingo, P., Diazaraque, R., Arribas, J. R., Gonzalez-Garcia, J. J., Montero, F., Sanchez, L., and Pahissa, Clin. Infect Dis. 2002, 34, 838846.

2. Kiser, J. J., Curr. Opin. HIV AIDS. 2008, 3(3), 330-341

\section{EXPLORING THE POTENTIAL OF BUCCAL DRUG DELIVERY FOR ENHANCING DRUG THERAPY}

\section{Thirumala Govender}

School of Pharmacy and Pharmacology, University of KwaZulu-Natal, Private Bag X54001 Durban, 4000, South Africa

Drug delivery via the buccal route has recently received increased interest in the literature as an alternative to oral and other conventional routes of administration for the following reasons: preparations administered via the buccal route are able to bypass enzymatic degradation and hepatic first pass 
metabolism thereby improving the systemic bioavailability of various drugs. Also, absorption following administration via the buccal route is not influenced by potential variations in the gastric emptying rate or the presence of food. This presentation will provide an overview of buccal drug delivery, approaches to enhance drug permeability across the buccal mucosae and advantages and limitations of current drug delivery systems being investigated. Examples of experimental studies currently being undertaken on buccal drug delivery with antihypertensives and antiretrovirals at UKZN will be presented.

The group has been focusing on optimizing the design of films as a buccal drug delivery system and examining the buccal permeability properties of various drugs. In a particular study, the aim was to prepare and characterise monolayered multipolymeric films (MMFs) comprising of a hydrophilic drug (Propranolol $\mathrm{HCl})(\mathrm{PHCl})$, and polymers of opposing solubilities. Films were prepared by emulsification and casted by a new approach using a silicone molded tray with individual wells. MMFs comprising of $\mathrm{PHCl}$ with Eudragit ${ }^{\circledR} 100$ (EUD100) and Chitosan (CHT), i.e., films with drug and polymers of opposing solubilities were successfully prepared (PHCl:EUD100:CHT; 1:10:0.5) and demonstrated uniform and reproducible drug content $(100.71 \pm 2.66 \%)$, thickness $(0.442 \pm 0.030 \mathrm{~mm})$, mucoadhesivity $(401.40 \pm 30.73 \mathrm{mN})$ and a controlled drug release profile. Drug release followed Higuchi's squareroot model. Maximum swelling of the films occurred after $1 \mathrm{~h}$ and $28.26 \%$ of the films eroded during the 8-h test period. Mechanical testing revealed that the MMFs displayed a greater abrasion resistance, were more elastic and also required more energy to break, rendering them tougher and more suitable for buccal delivery than the monopolymeric PHCl:EUD100 film. The inclusion of CHT to the film led to a more porous surface morphology. This study confirmed the potential of the above MMFs as a promising candidate for buccal delivery of $\mathrm{PHCl}$.

In another study, the buccal permeability potential of an antiretroviral drug, i.e., Didanosine was investigated. As the donor concentration increased from 5 to $20 \mathrm{mg} / \mathrm{ml}$, flux values increased statistically significantly $(P<0.05)$ from $25.94 \pm 1.35 \mu \mathrm{g} / \mathrm{cm}^{2}$ h to $71.57 \pm 3.12 \mu \mathrm{g} / \mathrm{cm}^{2} \mathrm{~h}$. A linear relationship $(R$ $\left.{ }^{2}=0.9557\right)$ between the steady-state flux and the donor concentrations of ddI indicated a passive diffusion transport mechanism for ddI. Aloe vera gel (AV gel) was identified as a novel buccal permeation enhancer with initial flux values increasing significantly with an increase in AVgel concentrations from 0.25 to $2 \%$ w/w. Light microscopic evaluation showed no visible differences in the thickness of the superficial layer of the epithelium, cell architecture, and cellular alignment of the mucosa in both the relevant control (PBS) and the treated (PBS/ddI or ddI/PBS/AVgel) mucosae. Ultrastructural analyses showed cellular damage in mucosae treated with $1.0 \%$ and $2.0 \%$ AVGel. These cells showed increased intercellular spacing, plasmalemma crenulation and mitochondria appeared translucent with little internal detail. Nuclear envelopes appeared distended and chromatin compacted and unevenly dispersed. In spite of this, desmosomal structure remained constant throughout all treatments. Data show that this antiretroviral drug has the potential for administration via the buccal route. These results suggest that AVgel is an effective buccal permeation enhancer, but its impact on cellular structure at concentrations above $0.5 \% \mathrm{w} / \mathrm{v}$ questions the safety of its potential use at concentrations higher than $0.5 \% \mathrm{w} / \mathrm{v}$.

\section{THE CASE FOR PLEASURE}

\section{Georges M. Halpern}

\section{Distinguished Professor of Pharmaceutical Sciences, Department of Applied Biology \& Chemical Technology, Hong Kong Polytechnic University, Hong Kong}

Poverty, unavailable clean water, corrupt politicians who squander public funds, pestilence, famine, wars and other man-made or blatantly ignored plagues kill people, make them ill and sick. Unless we address these seriously, medications will be just another pie-in-the-sky, or lipstick-on-a-pig, that will enrich the rich and make the poor poorer. But that is not all: the elephant-in-the-room is the Placebo. I shall provide recent references, including videos, but intend to concentrate on Pleasure proprio sensu. While stress may make you sick and belief could make you well, there are more than self-help guides to consult—and trust. If some foods, e.g., yogurt, have been inducted into the "Health Hall-of-Fame," further scrutiny shows that we only eat what we like, and the healthiest concoction will take a shortcut to the garbage bin if it does not titillate our senses. Sweetness induces analgesia at all ages. Chocolate beats Prozac $\AA$ and wine beats Valium ${ }^{\circledR}$ — because we enjoy them! Moderate enjoyable exercise-including sex—upregulates the immune response, while guilt will make you sick. 
When sick, a pleasant environment or flowering plants will reduce drug consumption, normalize vital signs, and shorten the course of the malady. Happiness makes us live longer and healthier.

Pleasure is not an "extra," or bonus bringing a little more soul to certain of our acts; it is a fundamental part of our animal life. It is just as difficult to define as spirit, but nonetheless humans are very conscious of it.

Pleasure is a potent drive, inducing forms of behavior adapted to physiological needs, e.g., temperature regulation and food-and-fluid intake; sensory pleasure is an incentive to useful behavior, and maximization of pleasure the answer to physiological conflicts and a much better life. And Pleasure is universally affordable.

\title{
FROM METHYLENE BLUE TO CHLOROQUINE TO THE MODERN ARTEMISININ ANTIMALARIAL ARTEMISONE: DEVELOPMENT AND CLINICAL ASPECTS
}

\author{
Ronald Wai Keung Wu, Ho-Wai Chan, Man-Ki Cheung, Kin-Wo Lee, Gigi Wing Chi Chan, \\ Richard K. Haynes
}

Department of Chemistry, The Open Laboratory of Chemical Biology, Institute of Molecular Technology for Drug Discovery and Synthesis, The Hong Kong University of Science and Technology, Clear Water Bay, Kowloon, Hong Kong. e-mail:haynes@ust.hk

The use of methylene blue by Ehrlich in 1891 represents the first example of the use of a totally synthetic compound for treatment of malaria. Although its use subsequently languished, it triggered an analogue search at Bayer Elberfeld in the 1920s, resulting in the development of the quinoline antimalarials sontochin, and, with eventual completion in other hands, the analogue resochin or chloroquine. The latter became the most successful single drug for the treatment of malaria; it was relatively well tolerated, affordable, and was the drug of choice in the World Health Organization (WHO) Global Eradication Program of the 1950s. However, the emergence of resistance to chloroquine that first appeared in Asia in the 1960s led to the demise of this drug. Fortunately, in the 1970s, artemisinin was discovered by Chinese scientists, and with the derivatives dihydroartemisinin (DHA), artesunate, and artemether have become front-line drugs for treatment of malaria in combination therapy with longer half-life drugs. ${ }^{1-3}$ However, artesunate is rapidly hydrolysed in vivo to DHA, and artemether is metabolized to DHA. The artemisinins, especially DHA, elicit neurotoxicity in laboratory screens ${ }^{4}$ and the sense of the problem is not diminished by a fatality induced by an artesunate overdose. ${ }^{5}$ Toxicity must be borne in mind, particularly if artemisinins are to be developed against other targets where protracted doses may be required. ${ }^{3}$ In a program designed to generate new artemisinins for use against malaria and other targets, we have enhanced drug permeability through the attachment of polar, nonmetabolizable groups at C-10. One such compound, artemisone, possesses negligible neurotoxicity, and is a designated development candidate. $^{6}$

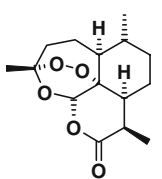

Artemisinin

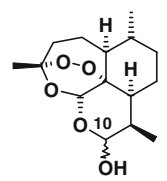

Dihydroartemisinin (DHA)
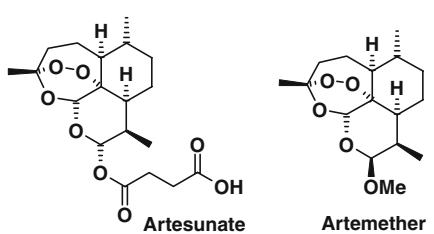

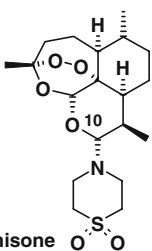

The lecture commences with a historical overview of development of synthetic antimalarials given above, provides a brief overview of current artemisinins, and then will include newer details on the development of artemisone that covers activity against cerebral malaria in a mouse model, other parasitic targets, and chemical behavior against various heme species including carboxy hemoglobin and carboxyheme. The latter results lead to the demise of the heme model for mode of action. ${ }^{6}$ 


\title{
References
}

1. R. K. Haynes, H.- W. Chan, C.- M. Lung et al. ChemMedChem 2007, 2, 1448-1463; R. K. Haynes, Curr. Med. Chem. 2006, 13, 509-537.

2. F. T. Aweeka, T. Francesca, P. I. German, Clin. Pharmacokinet. 2008, 47, 91-102; WHO World Malaria Report 2008, see http://www.who.int/malaria/wmr2008/.

3. S. Krishna, L. Bustamante, R. K. Haynes, and H. M. Staines, Trends Pharmacol. Sci., 2008, 29, 520527.

4. R. F. Genovese and D. B. Newman, Arch. Toxicol. 2008, 82, 379-385; S. Toovey, Toxicol. Lett. 2006, 166, 95-104.

5. S. Campos, P. de la Cerda, and A. Rivera, J. Pediatric Infect. Diseases, 2008, 3, 69-75.

6. R. K. Haynes, B. Fugmann, J. Stetter, et al. Angew. Chem. Int. Ed. 2006, 45, 2082-2088; D. Taramelli, R. K. Haynes, D. Monti, et al. ChemMedchem 2009, 4, in press.

\section{DRUG/DRUG INTERACTIONS AT THE LEVEL OF PLATELET CYCLOOXYGENASE}

\author{
T. Hohlfeld, A. Saxena, K. Schrör, D. Hafner \\ Heinrich-Heine-Universität Düsseldorf, Institut für Pharmakologie und Klinische Pharmakologie, \\ Moorenstrasse 5, 40225 Düsseldorf, Germany
}

Introduction Nonsteroidal antiinflammatory drugs (NSAIDs), including ibuprofen, naproxen and others, are among the most consumed and prescribed drugs worldwide. In addition to their known negative side effects, such as gastrointestinal ulcer and bleeding, recent studies suggested that NSAIDs may increase the risk of vascular events by attenuating the cardiovascular protection provided by low-dose aspirin. The mechanism of this drug/drug interaction is not well understood.

Methods In order to better explain this hypothetical interaction, we systematically analysed the antiplatelet effect of aspirin in the presence of NSAIDs. First, a computerized model was established to characterize the potential of NSAIDs to interfere with aspirin-induced platelet inhibition on the basis of enzyme kinetics, simulating the competition with aspirin at the level of platelet cyclooxygenase (COX-1). Subsequently, we experimentally substantiated the findings by studying the effect of aspirin in vitro on aggregation and thromboxane formation of platelets collected from healthy subjects in the presence of a broad selection of frequently prescribed NSAIDs at therapeutically relevant concentrations.

Results Mathematical simulation demonstrated that aspirin alone and high concentrations of NSAIDs inhibited platelet inhibition by aspirin, while lower concentrations of NSAIDs, resulting in incomplete inhibition of platelet COX-1 and thromboxane formation, largely prevented the irreversible inhibition of COX-1 by aspirin. Thus, the model predicted that subinhibitory concentrations of NSAIDs may lower the antiplatelet effect of aspirin.

This was confirmed by experimental studies with several NSAIDs, including ibuprofen, flufenammate, and piroxicam, as well as selected pyrazole analgesics, such as dipyrone and propyphenazone. However, several other NSAIDs, including diclofenac, indomethacin, and flurbiprofen, did not interfere with COX1 inhibition by aspirin (TX formation and aggregation). The differences between NSAIDs suggest that there are dissimilar binding modes to the substrate binding site of platelet COX-1, resulting in a different extent of drug/drug interaction with aspirin. Moreover, simulation as well as experimental results suggested that the studied interaction was competitive, i.e., platelet inhibition was restored by elevated concentrations of aspirin.

Conclusion Some NSAIDs, including ibuprofen, piroxicam, and pyrazoles interfere with aspirin at clinically relevant concentrations. Uncritical use NSAIDs may, therefore, attenuate or abolish cardiovascular protection by low-dose aspirin. However, there are remarkable differences between individual NSAIDs. 


\title{
DESIGN AND DEVELOPMENT OF NEW SYNTHETIC METHODS FOR BIOLOGICALLY IMPORTANT HETEROCYCLES
}

\section{H. Ila}

Jubilant Biosys Ltd., Jubilant Discovery Centre, \#96, Industrial Suburb, 2nd Stage, Yeshwanthpur, Bangalore 560 022, India

Small molecule heterocycles play an important role in drug discovery research and can exert powerful effects on the function of macrocycles that comprise living systems. Therefore, design and development of new pathways leading to efficient (three to five steps) synthesis of collection of small molecule heterocycles having skeletal and functional group (appendage site) diversity is emerging as an important area in both synthetic and medicinal chemistry. For the last several years, we have been utilizing polarized ketene dithioacetals and the corresponding $N, S$-acetals derived from them as versatile building blocks for a large number of biologically important five- and six-membered heterocycles displaying wide range of skeletal and functional group diversity. Our recent contribution in this will be presented in the lecture.

\section{References}

1. N. C. Misra, K. Panda, H. Ila, and H. Junjappa, J. Org. Chem. 2007, 72, 1246.

2. A. K. Yadav, S. Peruncheralathan, H. Ila, and H. Junjappa, J. Org. Chem. 2007, 72, 1388.

3. G. S. M. Sundaram, C. Venkatesh, H. Ila, and H. Junjappa, Synlett 2007, 251.

4. G. S. M. Sundaram, B. Singh, C. Venkatesh, H. Ila, and H. Junjappa, J. Org. Chem. 2007, 72, 5020.

5. C. Venkatesh, G. S. M. Sundaram, H. Ila, and H. Junjappa, J. Org. Chem. 2006, 71, 1280.

6. A. K. Yadav, S. Kumar, H. Ila, and H. Junjappa, Synlett, 2008, 965.

7. B. Singh, G. S. M.Sunderam, and H. Ila, Tetrahedron Lett. 2009, 50, 366.

8. S. Kumar, S. Peruncheralathan, and H. Ila, Org. Lett. 2008, 10, 965.

9. P. Singh, A. K. Yadav, and H. Ila, J. Org. Chem. 2009, 74, 5496.

10. S. Kumar, H. Ila, and H. Junjappa, J. Org. Chem. 2009, 74, 7046.

\section{GOMPHOSTENIN AND GOMPHOCRITINE: NEW ANTIMALARIAL COMPOUNDS FROM THE NATURAL SOURCE}

\author{
M. P. Kaushik \\ Discovery Center, Defence $R$ \& D Establishment, Jhansi Road Gwalior, MP, India
}

Malaria is one of the most important parasitic infections of humans due to its high morbidity and mortality with major consequent impact on economic productivity and livelihood. Approximately $40 \%$ of the world population lives in areas with the risk of malaria. Each year 300-500 million people suffer from acute malaria and 1.5-2.5 million die from the disease. Plasmodium falciparum, the causative agent of the malignant form of malaria, has high adaptability by mutation and is resistant to various types of antimalarial drugs. Thus, low-cost malaria treatments such as chloroquine and fansidar (sulfadoxine/ pyrimethamine) become ineffective with the selection and spread of mutant drug-resistant parasites and then to multidrug resistance emergence. Therefore, new drugs with novel mechanisms of action and that are structurally unrelated to existing antimalarial agents are thus urgently required. The ethnopharmacologial approach for the search of new antimalarial has proved to be more predictive with respect to malaria, quinine and its derivatives are still in use today, and new combination therapies based on artemisinin were recently introduced in the clinic.

As part of our continuing efforts directed toward the discovery of the structurally interesting and biologically active compounds from the Indian medicinal plants, three new clerodane diterpenes have 
been isolated, characterized and evaluated in vitro and in vivo for antimalarial properties against Plasmodium falciparum. The mode of action of these molecules was found to be different than that of choloquine.<smiles>CC(=O)OC[C@H]1C(OC(C)=O)CC(C)(C)C2(C)C=C(C)C(=O)C[C@H]1[C@H]2C/C=C/CO</smiles>

Gomphocritine<smiles>CC1=CC(=O)C[C@]2(C)[C@]1(C)CCC(CO)[C@@]2(C)CCC1=CCCO1</smiles>

Gomphostenin<smiles>CC(=O)OCC1CC[C@]2(C)C(C)=CC(=O)C[C@]2(C)[C@]1(C)CCC1=CCOC1=O</smiles>

Acetyl Gomphostenin

\title{
NOVEL POLYMERIC MICROREACTORS FOR BIO \& CHEMICAL SYNTHETIC APPLICATIONS
}

\author{
Dong-Pyo Kim \\ National Creative Research Center of Applied Microfluidic Chemistry, Chungnam National University, \\ Daejeon 305-764, Korea.e-mail: dpkim@cnu.ac.kr
}

Microreaction at lab-on-a chip system has been successfully used in synthetic, analytical chemistry, and bio-applications. In these applications, the microfluidic devices have been generally fabricated with durable glass, $\mathrm{Si}$ and metal by expensive MEMS fabrication techniques, alternatively with facile PDMS and PMMA by soft lithography techniques but low stability. Besides, it needs to develop the novel materials based microfluidics with high stability by facile fabrication process.

At this report, we introduce the successful fabrication of inorganic polymer-derived microchannels with organic solvent resistance and optical transparency, via economic micromolding process. The devices were fabricated by the commercial polysilazane, or polycarbosilane with photo- and thermal initiators. With the niche material-based microchannels between plastic and glass device, we demonstrated the reliable microchemical performance in various organic solvents at the different purposes. Moreover, the Pd catalytic and photochemical reaction also was discussed. Optically transparent inorganic polymer-derived microchannel showed excellent photocatalytic decomposition and sterilization effect, which is useful as an alternative photochemical microreactor of glass microreactor. And the separation process of chiral compounds in a triple laminar flow was demonstrated in the presence of stereospecific reactive enzyme. And also our updated achievement on the alternative types of microreactors, such as a sol-gel based hybrid resin-coated PDMS microchannel, etc. is also presented for efficient enzymatic chemical reactions by immobilizing the enzymes on the channel surface. On the other hand, a practical PDMS-based microchemical system with large gas-liquid contact area was successfully demonstrated for the boron-Heck reaction with highly improved reaction yield and selectivity. The novel polymeric microchannels can be a promising tool for various microchemistry and biotechnology applications. Finally, we may show several types of built-in microstructured microchannels which definitely enhance the uniqueness and performance of microfluidics.

\section{References}

1. Kim, D., et al., Lab on a Chip, 2008, 8, 1454.

2. Kim, D., et al., Lab on a Chip, 2009, 9, 1138.

3. Kim, D., et al., Advanced functional materials, 2009, 19, 1656. 


\title{
PROTEIN LIPIDATION INHIBITORS AS TOOLS TO STUDY CELLULAR FUNCTION: LESSONS LEARNT FROM THE PANCREATIC BETA-CELL
}

\author{
Anjan Kowluru \\ Departments of Pharmaceutical Sciences, Medicine and Surgery, Wayne State University and John D. \\ Dingell VA Medical Center, Detroit, MI 48201, USA
}

The majority of small molecular mass GTP-binding proteins (G-proteins) and the gamma subunits of trimeric G-proteins undergo a series of post-translational modification at their C-terminal cysteine residue. The first committed step in this reaction sequence is the incorporation of either a farnesyl (i.e., 15-carbon derivative of mevalonic acid; MVA) or geranylgeranyl (20-carbon derivative of MVA) groups; these signaling steps are catalyzed by farnesyltransferase (FTase) or geranylgeranyl transferase (GGTase), respectively. Using inhibitors of the biosynthesis of MVA (e.g., statins), a precursor for the biosynthesis of farnesyl or geranyl geranyl pyrophosphates, we first demonstrated relevance of this signaling pathway in glucose-stimulated insulin secretion (GSIS). Subsequent investigations from our laboratory using pro-drug inhibitors of protein lipidation (e.g., 3-allyl or vinyl farnesols and geraniols) yielded convincing support for regulatory roles for G-protein lipidation in GSIS. More recently, using peptidomimetic inhibitors of FTases (e.g., FTI-277) and GGTases (GGTI-2147), we not only verified aforementioned conclusions, but also identified specific small G-proteins (e.g., Rac1) involved in GSIS. These pharmacological observations were further confirmed by molecular biological approaches (e.g., overexpression of a dominant negative mutants or siRNA-mediated knock-down of endogenous FTase/ GGTase). Together, data from investigations have clearly implicated post-translational lipidation in betacell function. Potential defects (e.g., hypo/hyper regulation of these signaling steps) could contribute toward metabolic dysregulation (e.g., increase in oxidative stress and mitochondrial defects) and eventual demise of the islet beta-cell leading to the onset of diabetes. Potential therapeutic utility of lipidation inhibitors in the treatment and prevention of diabetes will be discussed.

\section{DIABETIC RETINOPATHY AND POTENTIAL THERAPEUTICS}

\section{Renu A. Kowluru}

Kresge Eye Institute, Wayne State University, Detroit, MI, USA

Retinopathy is one of the most debilitating microvascular complications that affect over $80 \%$ of patients with diabetes. Reactive oxygen species are elevated in the retina in diabetes, and this increases the permeability of mitochondrial membranes, and their DNA is damaged. These abnormalities are implicated in the pathogenesis of diabetic retinopathy via increasing apoptosis of retinal capillary cells. Using animal models of diabetic retinopathy, we have shown that antioxidants that inhibit diabetesinduced oxidative stress in the retina also have potential in preventing capillary cell apoptosis and histopathology characteristic of diabetic retinopathy. Further, our results have shown that overexpression of the enzyme responsible for scavenging mitochondrial superoxide (manganese superoxide dismutase) protects retina and its capillary cells from diabetes-induced abnormalities in the mitochondria, accelerated apoptosis and, also histopathological microvascular changes. However, clinical trials with antioxidants are very limited in numbers, and have produced somewhat ambiguous results. Although antioxidants are being used for other chronic diseases, controlled clinical trials are warranted to investigate the potential beneficial effects of antioxidants in the development of retinopathy in diabetic patients.

\section{BIOMOLECULAR CHEMISTRY DIRECTED TOWARDS DRUG DEVELOPMENT}

René Martin, ${ }^{1}$ Juliane Kirst, ${ }^{1}$ Sebastian Weidlich, ${ }^{1}$ Heinke Schieb, ${ }^{1}$ Georg Schlechtingen, ${ }^{1,3}$ A. Jäger, ${ }^{1}$ Lawrence Rajendran, ${ }^{4}$ Markus Böhl, ${ }^{5}$ Sabine Richter, ${ }^{5}$ Roman Fedorov, ${ }^{6}$ Dietmar J. Manstein, ${ }^{6}$ Herwig O. Gutzeit, ${ }^{5}$ Hans Klafki, ${ }^{2}$ Jens Wiltfang, ${ }^{2}$ Kai Simons, ${ }^{3,4}$ Hans-Joachim Knölker ${ }^{1,3}$ 
${ }^{1}$ Department Chemie, Technische Universität Dresden, Bergstr. 66, 01069 Dresden, Germany. e-mail: hans-joachim.knoelker@tu-dresden.de; ${ }^{2}$ Rheinische Kliniken Essen, Universität Duisburg-Essen, Virchowstr. 171, 45147 Essen, Germany; ${ }^{3} J A D O$ Technologies GmbH, Tatzberg 47-51, 01307 Dresden, Germany; ${ }^{4}$ Max Planck Institut für Molekulare Zellbiologie und Genetik, Pfotenhauer Str. 108, 01307 Dresden, Germany; ${ }^{5}$ Institut für Zoologie, Technische Universität Dresden, Zellescher Weg 20b, 01217 Dresden, Germany; ${ }^{6}$ Institut für Biophysikalische Chemie, Medizinische Hochschule Hannover, 30623 Hannover, Germany

Alzheimer's disease (AD) is a neurodegenerative disorder leading to progressive loss of memory and other cognitive abilities. Currently, there is no treatment for $\mathrm{AD}$ available which either stops the progress or can cure the disease. In cooperation with JADO Technologies (Dresden), the Max-Planck Institute for Molecular Cell Biology and Genetics in Dresden and the Laboratory for Molecular Neurobiology at the University Duisburg-Essen, we are developing an approach for the design of potential novel drugs against $\mathrm{AD}$. Characteristic of $\mathrm{AD}$ is the formation of extracellular aggregates of $\beta$-amyloid peptides, known as amyloid plaques. According to the amyloid cascade hypothesis, $\beta$ amyloid peptides are believed to play a key role in the pathogenesis. The $\beta$-amyloid peptides are generated from the membrane protein APP (amyloid precursor protein) by sequential cleavages of APP involving first, $\beta$-secretase, and subsequently, $\gamma$-secretase. Thus, highly efficient inhibition of the $\beta$ secretase enzyme should lead to a potential therapy for AD. Amyloidogenic cleavage of APP takes place when APP and $\beta$-secretase are co-internalized into the cell via endocytosis. $\beta$-Secretase is found in structural microdomains of the cell membrane, known as lipid rafts and cleavage of APP by $\beta$ secretase was reported to occur in lipid rafts. Based on these findings, we have designed and synthesized a modified lipophilic $\beta$-secretase inhibitor with a tripartite structure, in which each unit exhibits a well-defined function. ${ }^{1}$

$\beta$-Secretase Inhibitor: $\quad$ H-Glu-Val-Asn-Sta-Val-Ala-Glu-Phe-NH $2 \quad$ (GL 189)

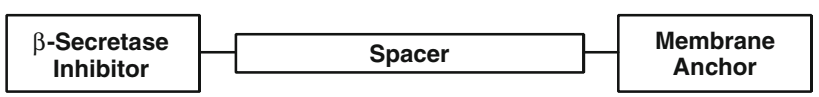

The known $\beta$-secretase inhibitor GL 189 (Calbiochem) is a transition state inhibitor showing only a minor effect in cellular assays. ${ }^{2}$ However, linking it to a membrane anchor via a spacer of defined length, leads to a tripartite structure which locates the $\beta$-secretase inhibitor to lipid rafts. The tripartite structure is transported into the cell by endocytosis and delivered to endosomes where $\beta$-secretase is active. ${ }^{1,3}$ The first results emphasized that our tripartite structures are more effective compared to nonlipophilic modified inhibitors, by several orders of magnitude - in cell culture as well as in animal models. In a mouse model simulating $\mathrm{AD}$, our novel inhibitor reduced the formation of $\beta$-amyloid peptides by $60 \%$ in only $4 \mathrm{~h}$, whereas the nonanchored inhibitor showed no effect.

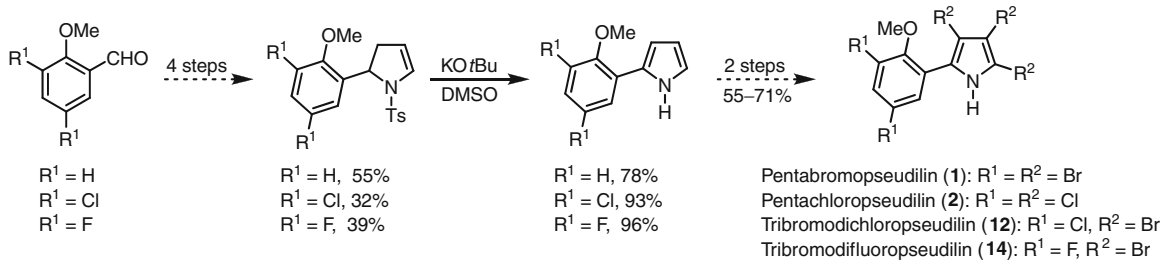

In a further project, we are developing novel inhibitors of myosin ATPase. Based on a silvermediated pyrrole synthesis described a few years ago, ${ }^{4}$ we have elaborated a highly efficient silvercatalyzed route which provided pentabromopseudilin (1) and pentachloropseudilin (2), halogenated natural products isolated from microorganisms, as well as their synthetic analogs 12 and $\mathbf{1 4} .^{5}$ These compounds have been identified as novel isoform-specific inhibitors of myosin motor activity. The activities of 1 and 2 are comparable to the known inhibitors (-)-blebbistatin (17) and $N$-benzyl-ptoluenesulfonamide (BTS) $(\mathbf{1 8}) .^{5-7}$ 


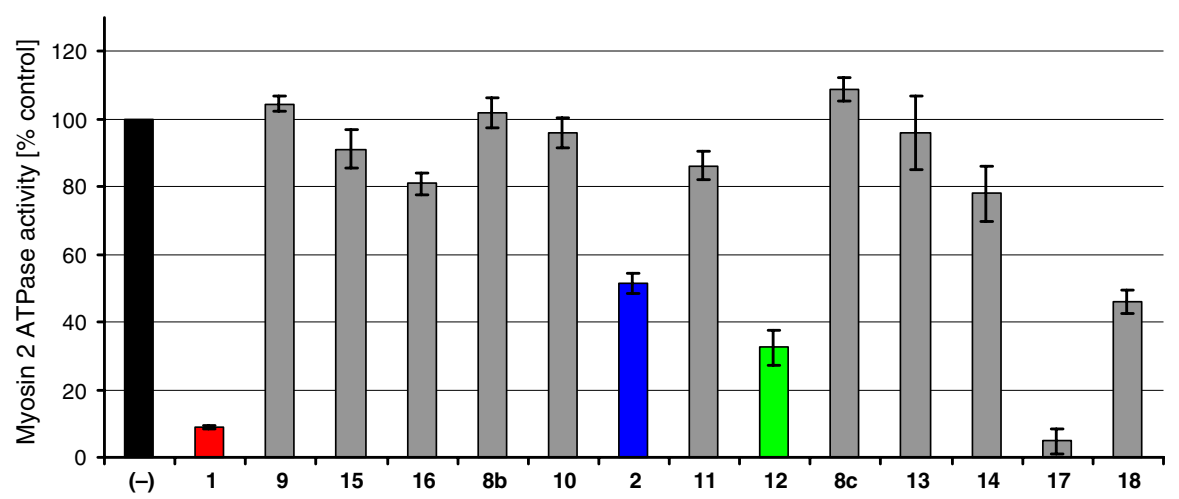

An X-ray crystal structure analysis of the complex formed by the Dictyostelium myosin-2 motordomain with $\mathrm{Mg}^{2+}-\mathrm{ADP}-m e t a$-vanadate and pentabromopseudilin (1) revealed a new allosteric binding site, $7.5 \AA$ away from the allosteric binding site of (-)-blebbistatin (17).

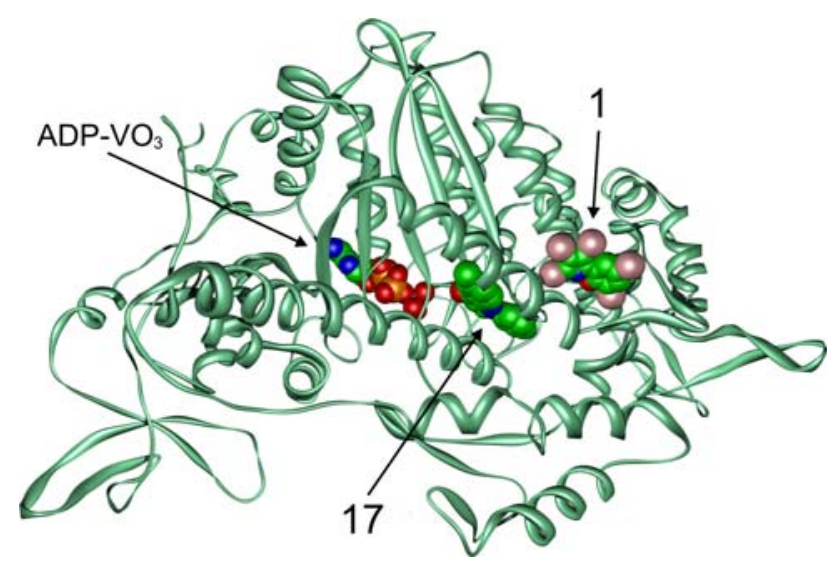

The discovery of a novel class of myosin ATPase inhibitors and the identification of a second allosteric-binding site opens up the way for the development of more potent isoform-specific myosin inhibitors based on rational drug design. Specific inhibitors of myosins represent promising candidates for the treatment of a range of diseases, such as cancer and malaria.

\section{References}

1. Braxmeier, T., Friedrichson, T., Fröhner, W., Jennings, G., Munick, M., Schlechtingen, G., Schroeder, C., Knölker, H.-J., Simons, K., Zerial, M., Kurzchalia, T., PCT Int Appl. WO 2005/ 097199, 2005.

2. (a) Tung, J. S., Davis, D. L., Anderson, J. P., Walker, D. E., Mamo, S., Jewett, N., Hom, R. K., Sinha, S., Thorsett, E. D., and John, V., J. Med. Chem. 2002, 45, 259; (b) Capell, A., Meyn, L., Fluhrer, R., Teplow, D. B., Walter, J., and Haass, C., J. Biol. Chem. 2002, 277, 5637.

3. Rajendran, L., Schneider, A., Schlechtingen, G., Weidlich, S., Ries, J., Braxmeier, T., Schwille, P., Schulz, J. B., Schroeder, C., Simons, M., Jennings, G., Knölker, H.-J., and Simons, K., Science 2008, 320, 520-523.

4. Agarwal, S. and Knölker, H.-J., Org. Biomol. Chem. 2004, 2, 3060-3063. 
5. Martin, R., Jäger, A., Böhl, M., Richter, S., Fedorov, R., Manstein, D. J., Gutzeit, H. O., and Knölker, H.-J., Angew. Chem. 2009, 121, 8186; Angew. Chem. Int. Ed. 2009, 49, 8042.

6. Manstein, D., Fedorov, R., Tsiavaliaris, G., Knölker, H.-J., Martin, R., Kirst, J., Gutzeit, H., Böhl, M., PCT Int. Appl. WO 2009/065600, 2009.

7. Fedorov, R., Böhl, M., Tsiavaliaris, G., Hartmann, F. K., Taft, M. H., Baruch, P., Brenner, B., Martin, R., Knölker, H.-J., Gutzeit, H. O., Manstein, D. J., Nat. Struct. Mol. Biol. 2009, 16, 80.

\title{
GOING AFTER THE OBVIOUS: INHIBITORS OF DE NOVO NUCLEOTIDE SYNTHESIS PATHWAY
}

\section{Lakshmi P. Kotra}

Scientist and Principal Investigator, Toronto General Research Institute; Director, Center for Molecular Design and Preformulations, University Health Network and University of Toronto, Toronto, ON M5G 1L7, Canada

Pyrimidine nucleotides are building blocks for the synthesis of RNA and DNA. Uridine monophosphate (UMP) serves as a key intermediate in the de novo pathway for the synthesis of pyrimidine nucleotides. Orotidine monophopshate decarboxylase (ODCase) is an important and efficient enzyme that accomplishes the ultimate step for the synthesis of UMP. Due to its important role in the de novo nucleic acid biosynthesis, ODCase is present in every species including bacteria, parasites such as plasmodia and humans, but not in viruses. In humans, pyrimidine nucleotides are synthesized via two routes: de novo and salvage pathways. Whenever higher concentrations of pyrimidines are needed in the cell including for the normal cellular processes, during uncontrolled growth of the cell such as in cancer, or during the fast replicating viral infections, etc., de novo pyrimidine synthesis is upregulated, and the activity of ODCase is simultaneously operating at a higher than normal levels. Our group has been interested in developing novel inhibitors of this enzyme as potential antiviral agents initially, and synthesized various C6-substituted pyrimidine nucleosides and nucleotides.

Initially, in collaboration with Emil Pai, we discovered that certain substitutions such as iodo and azido moieties would create covalent inhibitors to ODCase. Other substitutions such as a methyl or amino moieties would confer potent ODCase inhibitory properties to these molecules. Subsequent in vitro evaluation targeting malaria revealed that ODCase inhibitors could be potentially novel class of compounds targeting malaria. Select inhibitors also exhibited potent anticancer activities against cancers of hematopoietic origin. A collaborative effort is undertaken to further investigate the potential of ODCase inhibitors as potential antimalarial and anticancer agents, in vitro and in vivo. This talk will focus on the discoveries on the novel interactions between the ligands and the enzyme, and our efforts to develop this class of compounds as potential leads.

\section{METABOLITES-INSIGHTS INTO MICROBIAL DEFENCE SYSTEMS}

\author{
Hartmut Laatsch \\ Institute of Organic and Biomolecular Chemistry, University of Göttingen, Tammannstr. 2, \\ 37077 Göttingen, Germany.e-mail: hlaatsc@gwdg.de
}

Natural products are words and messages in a global communication system of species interactions. They have a special meaning and will effect an answer, which is not urgently constant, but depends on the given situation. Natural products are weapons and defence systems, attractants or repellents, or just communication signals, which are important for the survival of species. Also resistance development of bacteria against antibiotics is such a logical and unavoidable reply, which we can only overcome with a better vocabulary, i.e., with more and better drugs.

It follows that a continuous and efficient search for new natural products with potential application in medicine is a steady and indispensable task. However, since the number of natural products is limited, every newly isolated product will diminish the chances of further research. Two techniques have been applied to overcome this problem. One is the activity-directed high-throughput screening, which is an expensive and technical, but less intelligent process; the other one is the chemical screening. 
We are using a third one, a type of dragnet investigation, where we compare easily accessible data of more than 50,000 marine and microbial natural products from our databases, AntiBase or MarinLit, with our isolated and purified compounds. Comparison of substructures, NMR, MS, and UV data allows a very fast decision as to whether a given natural product is already known or not, which enables us to save time and money and avoid frustration.

New natural products often have existing parallels, which can be found with the same techniques. Others compounds are classified via their TLC/UV data or with our ESI MS/MS fragment libraries directly from crude extracts.

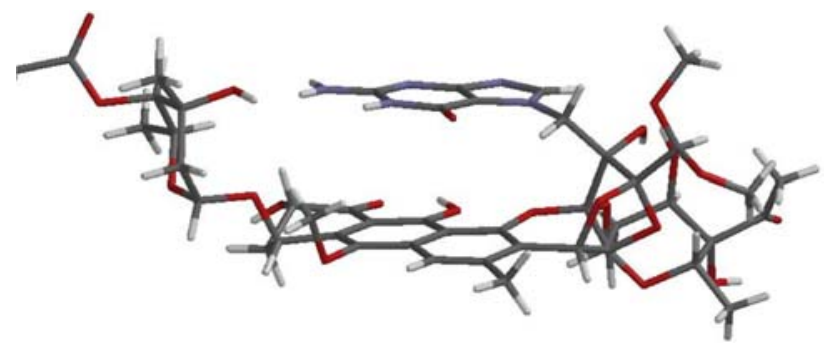

Fig. X-ray structure of gutingimycin

The presentation will explain modern dereplication techniques using recent examples from our ongoing research on marine bacteria. Database mining using HPLC/MS ${ }^{2}$, TLC/UV, and TLC/DESI-MS techniques will be compared.

\title{
CYTOTOXIC REACTIVE CARBONYL SPECIES (RCS): FROM METABOLIC STUDIES TO THE DISCOVERY OF NOVEL RCS SEQUESTERING AGENTS
}

\author{
Marica Orioli, Marina Carini, Giancarlo Aldini \\ Department of Pharmaceutical Sciences "P. Pratesi”, Università degli Studi di Milano, Via Mangiagalli \\ 25, 20133, Milan, Italy.e-mail: marica.orioli@unimi.it
}

Reactive carbonyl species (RCS), such as $\alpha, \beta$-unsaturated aldehydes [4-hydroxy-trans-2-nonenal (HNE), acrolein (ACR)], dialdehydes [malondialdehyde (MDA), glyoxal (GO)], and levuglandines are important cytotoxic mediators leading to alteration of the cellular function and involved in several physiopathological conditions including diabetic-related diseases, age-dependent tissue dysfunction, and metabolic distress syndrome. The main detoxification pathways of RCS involve oxidation-reduction of the carbonyl function, and glutathione (GSH) conjugation by GSH-S-transferases. More recently, by using a peptidomic mass spectrometric approach, we identified endogenous histidine dipeptides, such as carnosine ( $\beta$-alanyl-L-histidine, CAR), as additional nucleophilic agents able to detoxify the $\alpha, \beta$ unsaturated aldehydes through a Michael adduction. ${ }^{1}$ This novel metabolic pattern has been then confirmed in vivo in the Zucker obese rats, a well-established animal model of carbonyl damage, by detecting in urine the Michael adduct CAR-HNE. When RCS are massively generated, or when the detoxification systems are hampered, RCS covalently react with several macromolecules such as DNA and proteins, leading to cell and tissue damages. Hence, RCS are a potential drug target and there is great interest in searching novel bioactive molecules effective in detoxifying these compounds through a direct mechanism (RCS sequestering effect), or by restoring/ameliorating the metabolic efficiency. ${ }^{2}$ Although CAR is a selective and endogenous quencher of RCS, its pharmacological use is limited since it is rapidly hydrolyzed by a specific serum dipeptidase (carnosinase). Hence, we were aimed to derive CAR analogues characterized by (i) carnosinase stability and (ii) a greater reactivity toward RCS, even maintaining the same selectivity. The stability was reached by the isomerization of L- to D-histidine, leading to $\beta$-alanyl-D-histidine (D-carnosine, D-CAR), which is not recognized by carnosinase, but maintains the same quenching activity of L-CAR. The increase of reactivity was reached by modulating 
the conformational profile of the Schiff's base intermediate, in order to favor a close conformation in which the imidazole ring approaches enough the C3 of the Schiff's base to form the corresponding Michael adduct. A series of D-CAR derivatives was analyzed by in silico approaches to find out those characterized by a favorable folded conformational profile. The most promising was synthesized and the stability and quenching ability evaluated. By this way, a set of phenyl derivatives was identified, characterized by high stability in human plasma, and by a nearly doubled HNE-quenching ability compared to D-CAR.

\title{
References
}

1. Aldini, G., et al. Carnosine is a quencher of 4-hydroxy-nonenal: through what mechanism of reaction? Biochem. Biophys. Res. Commun. 2002, 298(5), 699-706.

2. Aldini, $\mathrm{G}$ et al. Lipoxidation-derived reactive carbonyl species as potential drug targets in preventing protein carbonylation and related cellular dysfunction. ChemMedChem. 2006, 1(10), 1045-1058.

\section{POLYCYCLIC CAGE STRUCTURES AS LIPOPHILIC SCAFFOLDS FOR NEUROPROTECTIVE DRUGS}

\author{
Sarel F. Malan \\ School of Pharmacy, University of the Western Cape, Private Bag X17, Bellville, South Africa and School \\ of Pharmacy, North-West University, Potchefstroom, South Africa.e-mail: sfmalan@uwc.ac.za
}

The lethal triplet of metabolic compromise, oxidative stress, and excitotoxicity may act separately or cooperatively to cause neuronal cell death. Intracellular calcium homeostasis, or rather the lack thereof, has in many studies been implicated in neuronal degeneration and is currently believed to be one of its main causes. Intracellular calcium overload leads to the activation of various enzyme systems, as well as intracellular accumulation of free radicals and thus oxidative stress. These and other calcium-related processes ultimately lead to cell death and neurodegeneration. Earlier studies evaluating the biological activity of the polycyclic cage amines indicated activity that includes amongst others, L-type calcium channel antagonism-leading to possible neuroprotective activity - and high affinity for the sigmabinding site. The potential antiparkinsonian and neuroprotective activity of the pentacycloundecylamine and D3-trishomocubane derivatives was demonstrated in the MPTP parkinsonian mouse model and is thought to reside primarily in the observed sigma receptor antagonism and ion channel modulating effects thereof. Inhibition of the dopamine transporter could also be of importance in this model. Based on this information and the structural similarities of the polycyclic cage amines and memantine, a series of functionalized cage compounds was synthesized and evaluated for neuroprotection through various, and possibly dual or multiple mechanisms. The highly lipophilic polycyclic cage was also utilized in a prodrug strategy to afford blood-brain barrier permeability to drugs with known antioxidant and possible neuroprotective potential.

In these studies, the polycyclic cage has proven to be a excellent scaffold for design of neuroprotective compounds and it is postulated that derivatives thereof could yet be of therapeutic value in the treatment of neurodegenerative disorders like Parkinson's and Alzheimer's disease.

\section{TELOMERE LENGTH MAINTENANCE AS A TARGET FOR ANTICANCER DRUG DISCOVERY}

\author{
K. Muniyappa \\ Department of Biochemistry, Indian Institute of Science, Bangalore 560012, India
}

Telomeres are distinctive structures, composed of tandemly repeated DNA sequences and associated proteins that cap the ends of all eukaryotic chromosomes. Telomeres are essential for maintaining the integrity and stability of eukaryotic genomes. In mammals, the length, structure, and function of telomeres 
have been believed to contribute to cellular and organismal phenotypes associated with cancer and aging. Telomere length is regulated by telomerase-dependent and telomerase-independent mechanisms. Drugs that directly bind to the telomeres and stabilize secondary DNA structures such as G-quadruplexes are potent inhibitors of telomerase; consequently, these could serve as new targets for cancer therapy. I will discuss what is known about the basis for the links between telomeres, aging and cancer, and some of the known and proposed consequences of telomere dysfunction in normal and cancer cells

\title{
NATURE-A VALUABLE PLATFORM FOR NEW DRUG DISCOVERY
}

\author{
M. D. Nair \\ Formerly Vice President, SPIC Pharmaceuticals, A-11, Sagarika No. 15, 3rd Seaward Road, Valmiki \\ Nagar, Thiruvanmiyur, Chennai 600 041, TN, India.e-mail: e-mdnair@vsnl.com
}

The global R\&D based pharmaceutical companies which have been responsible for the discovery, development, manufacture, and distribution of new drugs to the patients who need them, is today at the cross roads. While trying to re-establish its ability to survive and grow in an environment of declining pipelines of new products, low productivity, escalating costs, low returns due to decrease in exclusivity for products in the market place due to patent expiries, fast eroding public image, and pressure on costs and prices, it is obvious that an introspection of its current business and R\&D models has become imperative.

While many new models for drug discovery are being actively pursued by the R\&D based pharmaceutical companies including systems biology and modern genomics and proteomics based approaches, they are yet to deliver novel drugs or drug leads in any significant way. In addition, there is no indication that these approaches have the potential to reduce the costs of drug discovery and development and speed up the process to provide drugs which are more affordable to the masses.

In the history of new drug discovery, natural products, primarily plant-based ones have played a major role. However, due to lack of sustained scientific efforts, low success rates, complex nature of candidate drugs, and difficulties in patenting the products due to their origin being natural resources, for the last five decades there has been a decline in interest. In this area in recent times due to the very poor pipeline for new drugs in spite of massive investments, disillusionment of chemicals based drugs, back to nature attitudes, better understanding of disease processes, relaxation of regulatory requirements for plant-based drugs and the long track record of safe use of such drugs in traditional systems of medicine, there is a resurgence of interest in exploring the vast potential that these approaches offer. Since the sixties, for the next four decades, except for Paclitaxel and artemesinin, very few products including antibiotics have been discovered and developed from natural products. However, during the period 2005-2007, 13 new drugs of which five are first members of new classes were approved by the U.S. FDA. Even by modern standards, natural products are the largest depository of combinatorial libraries which for sheer numbers and diversity, can never be replicated through chemical means. With appropriate in vitro and in vivo screening models, it is possible to discover new drugs from natural products to complement the available therapies and meet unmet medical needs.

This presentation will dilineate a very practical, scientific and integrated approach to exploit natural products for the discovery of novel drugs for diseases for which no satisfactory therapy is available or the available ones are unsuitable or inadequate.

\section{APPRAISAL OF OZONE AS BIOLOGICALLY ACTIVE MOLECULE AND EXPERIMENTAL TOOL IN BIOMEDICAL SCIENCES}

\author{
Douglas W Oliver, Christiaan B. Brink, Brian H. Harvey, Mmalebuso L Mokoena \\ Unit for Drug Research and Development, School of Pharmacy, North-West University Potchefstroom \\ Campus, Private Bag X6001, Potchefstroom 2530, South Africa
}

Ozone $\left(\mathrm{O}_{3}\right)$ is a major air pollutant and is well-known for its very strong oxidative actions with beneficial effects in purifying various matrixes resulting in a variety of potential uses, in view of its antimicrobial and deodorizing properties. Ozone is frequently used for chemical industrial applications replacing chorine as a purifying and sterilizing agent for matrixes such as air, water, and soil. In recent years, there 
has been an ever increasing interest in ozone for its beneficial potential in biological systems. Ozone also converts to reactive oxygen species (ROS) upon contact with biological membranes, which ultimately are responsible for its systemic oxidative effects. On the other hand, ozone has been proposed as a cellular metabolic activator and immunomodulator. Numerous reports have entered the literature on the medicinal application of ozone in alternative medicine. The majority of the data from these reports on the clinical application of ozone in the human has come from uncontrolled investigations. Medicinal claims are made as far reaching as amongst others the ozone treatment of HIV/AIDS.

The concerns viewed during several international forums in recent years on the safety and potential inappropriate medicinal use of ozone prompted us to conduct several investigations on the biological activity of ozone. Experimental design was performed to administer ozone acutely and chronically to intact test animals in in vivo exposure models to investigate and provide evidence of proof of concept of such animal models for ozone treatments. The successful experimental model design allowed for the dose and time investigations of inhaled ozone. These controlled ozone studies demonstrated that the model is effective to investigate the biological activity of ozone as well as the mechanisms involved in the ozoneinduced oxidative stress in both normal- and disease-induced animals. These studies also indicated that the responses after ozone treatments differ in a concentration-dependant manner with respect to acute versus chronic treatments.

In conclusion, these investigations not only yielded information on the safety and biological activity of ozone, but also provided evidence that ozone is a unique pharmacological and toxically experimental tool for investigations that involves oxidative stress conditions in biological systems. The data from these studies further emphasize caution for the systemic used of ozone for medicinal purposes view of its complex activities and actions.

\section{COMPUTER-ASSISTED PREDICTION AND DESIGN OF MULTITARGETED DRUGS}

\section{Vladimir Poroikov}

Institute of Biomedical Chemistry of Rus. Acad. Med. Sci., 10, Pogodinskaya Str., Moscow 119121, Russia.e-mail: vladimir.poroikov@ibmc.msk.ru

During the XX century, the dominant paradigm in creation of new drugs was based on suggestion about selectivity of action on a certain molecular target, which should lead to the normalization of pathological process. At the same time, the majority of known drugs interact with several or even many targets in the organism; however, such action is mostly associated with unwanted adverse effects and toxicity.

After the deciphering of human genome and first results achieved in postgenomic studies, it became obvious that many diseases have a complex etiology, while drug action on a certain target often leads to activation/blockade of other elements in the appropriate regulatory network. As a consequence of negative feedbacks, expected pharmacotherapeutic action may be significantly decreased or even completely suppressed. The multitargeted drugs concept appears, according which such remedies due to the additive, synergistic, or antagonistic action might have some advantages comparing to the monotargeted medicines.

Discovery of new multitargeted drugs requires the solution of two tasks: (1) identification of targets which could be blocked or activated to achieve the desirable pharmacotherapeutic effect, and (2) finding of ligands that interact with the identified targets in a desirable mode. The first aim could be achieved by simulation of behavior in regulatory network blocking or activating certain nodes (targets) and their combinations. The second aim could be achieved either by prediction of biological activity spectra for molecules from different databases and selection of hits with the requested biological profiles, or by direct computer-aided design of multitargeted ligands. Possibilities and limitations of current bioinformatics and computer-aided drug design methods in discovery of particular molecular targets and their multiple ligands will be discussed.

\section{Acknowledgments}

This work was partially supported by European Commission FP6 Grant LSHB-CT-2007-037590 'Net2Drug' and ISTC grant 3777. 


\title{
NANOPLATFORM FOR TUMOR IMAGING AND THERAPY
}

\author{
Ravindra K. Pandey
}

Photodynamic Therapy Center, Roswell Park Cancer Institute, Buffalo, NY 14263, USA

Both cancer detection and treatment depend on selective delivery of appropriate agents to the malignancy. Photodynamic therapy (PDT), a relatively new modality for the treatment of a variety of oncological, cardiovascular, dermatological, and ophthalmic diseases, is based on the preferential localization of photosensitizing molecules (PS) in target tissue. Upon light absorption, the PS produces reactive singlet oxygen which damages tumor cells and neovasculature, and also initiates anti-tumor inflammatory and immune responses. We and others have developed relatively tumor-avid PS which selectively accumulates in tumors in vivo, and these molecules have been used to carry optical, PET, and MR imaging agents to the tumor sites. However, the tumor selectivity of current PS is not always adequate. Approaches of linking PS to antibody fragments or receptor ligands have been disappointing because the number of required PS/cell generally is lower than the number of antigen- or receptor-binding sites. Conversely, the imaging agent carrying capacity of individual PS molecules is limited.

Nanotechnology platforms potentially can deliver large numbers of PS and/or imaging agents to tumors. Nanoparticles (NP) are uniquely promising in that (i) their hydrophilicity and charge can be altered; (ii) they possess enormous surface areas and their surface can be modified with functional groups possessing a diverse array of chemical and biochemical properties, including tumor-selective ligands; (iii) owing to their subcellular and submicron size, they can penetrate deep into tissues and generally are taken up efficiently by cells; (iv) since numerous strategies for the preparation of nanomaterials are already in place, PS-loaded nanoparticles can be made by numerous methods, such as covalent linkages or selfassembly.

For the last 5 years, we have been working on biocompatible organically modified ormosil and polyacrylamide nanoparticles, which can be used to develop multifunctional nanovectors for tumor therapy and imaging (optical and PET) in injectable formulations for safe and efficient trafficking to tumor tissues in vivo.

We have collected strong supporting evidence for the vision of the comprehensive development, characterization, and validation of multifunctional nanovector platforms that can deliver tumor-avid therapeutic photosensitizers that are only active (and toxic) when illuminated by specific wavelengths of light, and also carry one or more imaging agents; thus enabling both multimodal diagnosis and imageguided therapy. Tumor selectivity is achieved from the tumor avidity of the PS and/or from peptide ligands recognized by target cells as well as from the local activation of the PS. The synthesis and biological significance of these nanoparticles will be presented.

\section{References}

1. Pandey, R. K. et al., Nature: a rich source for developing multifunctional agents. Tumor-imaging and photodynamic therapy. Lasers Surg. Med. 2006, 38, 445-467, and references therein.

2. Pandey, R. K. Lighting up the lives of cancer patients by developing drugs for tumor-imaging and photodynamic therapy. Oncol. Issues, March/April 2008.

3. Pandey, R. K. et al., Organically modified silica nanoparticles with covalently incorporated photosensitizer for photodynamic therapy of cancer. Nano Lett., 2007, 7(9), 2835-2842.

\section{OMARKERS AS SURROGATE ENDPOINTS IN CLINICAL TRIALS}

\section{Bernd Rosenkranz}

Division of Pharmacology, Department of Medicine, Stellenbosch University, Tygerberg, Cape Town 7505, South Africa.e-mail: rosenkranz@sun.ac.za 
A biomarker $(\mathrm{BM})$ is "a characteristic that is measured and evaluated as an indicator of normal biological processes, pathogenic processes, or pharmacological responses to a therapeutic intervention" (FDA-NIH Consensus Conference 1999). BMs can reduce cost and duration of drug development. During early clinical development, they are useful for demonstrating "proof of concept," for selecting the best clinical candidate or for dose finding. A BM can be qualified to the status of a surrogate endpoint (SEP) "that is intended to substitute for a clinical endpoint and that is expected to predict clinical benefit (or harm, or lack of benefit or harm) on the basis of epidemiological, therapeutic, pathophysiological, or other scientific evidence" (Biomarker Definitions Working Group 2001), if the following conditions are met: (a) biological plausibility, (b) statistical relationship between surrogate and clinical outcome, and (c) treatment effects on the surrogate correspond to outcome in clinical studies. Examples for efficacy SEPs include CD4 count/ HIV1 viral load for ARVs, tumor imaging or progression-free survival for chemotherapy, blood pressure or LDL for cardiovascular drugs, or $\mathrm{HbA}_{1 \mathrm{c}}$ for antidiabetics. QTc, a safety SEP for sudden death due to "torsades de pointes," has become a mandatory FDA requirement for NDA submissions.

Several biologically plausible BMs have been shown not to be related to the proposed associated clinical endpoints. For example, premature ventricular contractions after myocardial infarction were considered to be a key trigger of sudden cardiac death. Very unexpectedly, however, a large clinical trial (CAST 1991) revealed that treatment with class 1 antiarrhythmics led to a significant increase in mortality in this patient population. Other examples for failures of SEPs include bone mineral density to predict osteoporotic fractures across drug classes, or negative inotropic effect of betablockers to predict an unfavorable outcome in congestive heart failure. Appropriate qualification and validation of BMs are absolutely mandatory for their successful use as SEP in drug development. Both FDA and EMEA have recognized the continued need for addressing this topic. As of 2009, the FDA sponsors a project "Qualification of Biomarkers and Surrogate Endpoints in Chronic Disease" together with the US Institute of Medicine (HCSX-H-08-06-A); in the same year, the EMEA have formalized a new Scientific Advice procedure for qualification of biomarkers in a research and development context.

\title{
LIPOTEICHOIC ACIDS OF GRAM-POSITIVE BACTERIA-SYNTHESIS AND SOME BIOLOGICAL PROPERTIES
}

\section{Richard R. Schmidt}

\begin{abstract}
Fachbereich Chemie, Universität Konstanz, Fach 725, 78457 Konstanz, Germany. e-mail: richard.schmidt@uni-konstanz.de
\end{abstract}

Gram-positive bacteria are causing many infectious diseases; nevertheless, these bacteria are not as well understood as gram-negative bacteria. It is assumed that amongst the immunoactive constituents of grampositive bacteria are lipoteichoic acids (LTAs). They are amphiphilic, negatively charged, structurally quite different glycolipids that were classified into four types (type I-IV). The most frequently isolated grampositive pathogen causing infections is Staphylococcus aureus possessing an LTA classified as type I that has been synthesized in our group and biologically evaluated. LTAs that also gained great interest are type II LTA isolated from Lactococcus garvieae and particularly type IV LTA 1 isolated from Streptococcus pneumoniae, respectively. All three LTAs are structurally quite different, but they are believed to interact with the innate immune system in a similar fashion, which is by stimulation of TLR2. Hence, chemical syntheses leading to structurally defined material should have a major impact on these studies.

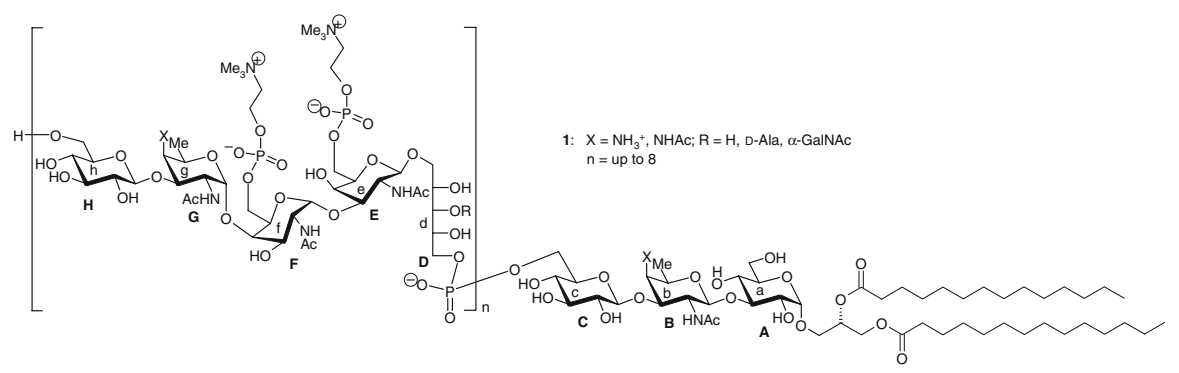




\title{
DOMINO AND CHIRAL POOL APPROACHES FOR BIOLOGICALLY ACTIVE NATURAL PRODUCT SYNTHESIS: TOWARDS NEW PHARMACOPHORES
}

\author{
Siméon Arseniyadis \\ Centre de Recherche de Gif, Institut de Chimie des Substances Naturelles, CNRS, 91198 Gif-sur-Yvette \\ Cedex, France.e-mail: simeon.arseniyadis@icsn.cnrs-gif.fr
}

Around $50 \%$ of antibiotic, antitumor, antiviral, immunosuppressants, anticholesterol, antidiabetic drugs derive from secondary metabolites. The iridals comprise several families of monocyclic, bicyclic, or spirocyclic A-seco triterpenes that have in common a central B-ring nucleus. Discovered by Marner et al., they show a broad range of biological activities including anti-tumor, MDR reversal, antiplasmodial, membrane reinforcing, and protein kinase $\mathrm{C}$ activation. ${ }^{1}$ Galbanic acid, itself an A-seco sesquiterpene coumarin ether, shows a range of biological activities such as antibiotic, antibacterial, antithrombotic, and hepatoprotective activities. ${ }^{2}$ The compound is also a potent antifertility and hormonal lead. It was demonstrated to synergize with various antibiotics opening up promising applications for the treatment of methicillin-resistant Staphylococcus aureus infections.

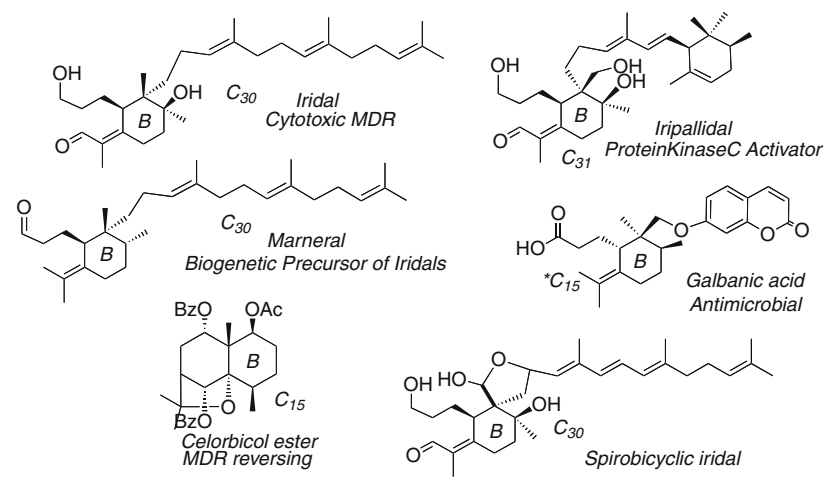

Very recently, methyl-galbanate and galbanic acid were screened in an in vitro anti-influenza A viral $\left(\mathrm{H}_{1} \mathrm{~N}_{1}\right)$ assay, with amantadine $\left(\mathrm{IC}_{50} 0.92 \mathrm{mg} / \mathrm{ml}\right)$, as a positive control. They are reported to show good potency against influenza A virus $\mathrm{H}_{1} \mathrm{~N}_{1}\left(\mathrm{IC}_{50} 0.26\right.$ and $\left.0.45 \mathrm{mg} / \mathrm{ml}\right)$, with the methyl-galbanate showing better potency than its corresponding free acid. Sesquiterpenes from Celastraceae are promising candidates in cancer chemotherapy. The interesting biological profile of these natural products, along with their challenging molecular structures, led us to embark on their synthesis. Compounds accessed from these endeavors are candidates for pharmaceutical development in the area of antiproliferating activity, malaria, influenza, fertility control, and combined therapy. Since both targeted families (iridalsgalbanic acid) fall within the boundaries of Lipinski's rules, prospects for pharmaceutical development are promising, once lead compounds have been identified. Routes toward the target structures in this project were designed in such a way as to allow structural simplification and variation of the natural iridal and galbanic acid framework. To the best of our knowledge, there have been no studies on the mode of action of iridal and its congeners at the molecular level, since there is no literature report on systematic SAR work for iridals so far. Bearing a significantly less complex structure compared with taxol, and therefore easier to synthesize, iridals could represent new chemotypes for microtubule inhibition. Within the time limits, iridal, ${ }^{3}$ marneral (the biogenetic precursor of all iridals), and galbanic acid ${ }^{4}$ syntheses will be presented in reasonable detail.

\section{References}

1. Marner, F.-J., Curr. Org. Chem. 1997, 1, 153. 
2. Bagirov, V. Y., Scheichenko, V. I., Veselovskaya, N. V., Sklyar, Y. E., Savina, A. A., Kir'yanova, I. A. Khim. Prir. Soedin. 1980, 16, 620; Appendino, G., Tagliapetra, S., Nano, G. M., Jakupovic, J., Phytochemistry, 1994, 35, 183.

3. Corbu, A., Aquino, M., Pratap, T.V., Retailleau, P., and Arseniyadis, S., Org. Lett. 2008, 10, 1787.

4. Corbu, A., Perez, M., Aquino, M., Retailleau, P., and Arseniyadis, S., Org. Lett. 2008, 10(13), 2853; Corbu, A., Aquino, M., Perez, M., Gandara, Z., Retailleau, P., and Arseniyadis, S., Eur. J. Org. Chem. 2009, (01021, in press).

\title{
FIGHTING AGAINST TUMOURS
}

\author{
Giovanni Petrillo, ${ }^{1}$ Domenico Spinelli, ${ }^{2}$ Maurizio Viale ${ }^{3}$ \\ ${ }^{1}$ Dipartimento di Chimica e Chimica Industriale Università di Genova, Via Dodecaneso 31, 16146 \\ Genova, Italy.e-mail: petrillo@ chimica.unige.it; ${ }^{2}$ Dipartimento di Chimica 'G. Ciamician' Università di \\ Bologna, Via Selmi 2, 40126 Bologna, Italy.e-mail: domenico.spinelli@unibo.it; ${ }^{3}$ Istituto Nazionale per \\ la Ricerca sul Cancro, S.C. Terapia Immunologica, Largo R. Benzi 10, 16132 Genova, Italy. e-mail: \\ maurizio.viale@istge.it
}

Different strategies are normally used in the fight against tumours. In the presence of localized malignancies surgery and radiotherapy are usually effectively employed. In contrast, the occurrence of metastatic tumours requires treatment based on chemotherapy supported by immunotherapy or by modifiers of biological response, often able to improve the response rate at least in selected cases.

Notwithstanding the efforts in this field and some unquestionable improvements, the chemotherapy's effectiveness is still quite low for most cancer types such as ovary, colon, lung, kidney, pancreas, and liver cancers. Perhaps the most important cause of failure depends on the development of intrinsic and acquired drug resistance by the tumour cells that causes disease relapse because of some specific or more general cellular mechanisms which provide tumour cells with the ability to resist chemotherapy.

To gain more and more instruments in the fight against tumours, we have developed the synthesis of new compounds able to behave as potential antitumor drugs or promising lead structures and also of new compounds able to contrast the phenomenon of multidrug resistance (MDR).

In the lecture, the synthesis of some relevant classes of compounds will be described and some recent results on their biological activities illustrated.

\section{References}

1. Parkin, D. M., Bray, F., Ferlay, J., and Pisani, P., Global cancer statistics, 2002. CA Cancer J. Clin. 2005, 55, 74-108.

2. Parkin, D. M., Global cancer statistics in the year 2000, Lancet Oncol 2001, 2, 533-543.

3. Gatti, L., Beretta, G. L., Cossa, G., Zunino, F., and Perego, P. ABC transporters as potential targets for modulation of drug resistance. Mini Rev. Med. Chem. 2009, 9, 1102-1112.

4. O'Connor, R., A review of mechanisms of circumvention and modulation of chemotherapeutic drug resistance. Curr. Cancer Drug Targets, 2009, 9(3), 273-280.

5. Dell'Erba, C., Chiavarina, B., Fenoglio, C., Petrillo, G., Cordazzo, C., Boncompagni, E., Spinelli, D., Ognio, E., Aiello, C., Mariggiò, M. A., and Viale, M., Inhibition of cell proliferation, cytotoxicity and induction of apoptosis of 1,4-bis(1-naphthyl)-2,3-dinitro-1,3-butadiene in gastrointestinal tumour cell lines and preliminary evaluation of its toxicity in vivo. Pharmacol. Res., 2005, 52, 271.

6. Petrillo, G., Fenoglio, C., Ognio, E., Aiello, C., Spinelli, D., Mariggiò, M. A., Maccagno, M., Morganti, S., Cordazzo, C., and Viale, M. Naphthylnitrobutadienes as pharmacologically-active molecules: evaluation of the in vivo antitumour activity. Invest New Drug, 2007, 25, 535

7. Petrillo, G., Mariggiò, M. A., Fenoglio, C., Aiello, C., Cordazzo, C., Morganti, S., Rizzato, E., Spinelli, D., Maccagno, M., Bianchi, L., Prevosto, C., and Viale, M., Design, synthesis and in vitro 
evaluation of new naphthylnitrobutadienes with potential antiproliferative activity: towards a structure/activity relationship. Bioorg. Med. Chem, 2008, 16, 240.

8. Viale, M., Petrillo, G., Maccagno, M., Castagnola, P., Aiello, C., Cordazzo, C., Mariggiò, M. A., Jadhav, S. A., Bianchi, L., Leto, G., Rizzato, E., Poggi, A., and Spinelli, D. Sensitivity of different resistant tumour cell lines to the two novel compounds (2Z,4E)-2-methylsulfanyl-5-(1-naphthyl)-4nitro-2,4-pentadienoate and (1E,3E)-1,4-bis(2-naphthyl)-2,3-dinitro-1,3-butadiene. Eur. J. Pharmacol., 2008, 588, 47.

9. Viale, M., Cordazzo, C., Cosimelli, B., De Totero, D., Castagnola, P., Aiello, C., Severi, E., Petrillo, G., Budriesi, R., Cianfriglia, M., and Spinelli, D., Inhibition of MDR1 activity in vitro by a novel class of diltiazem analogues: towards new candidates. J. Med. Chem., 2009, 52, 259-266.

10. Viale, M., Cordazzo, C., de Totero, D., Budriesi, R., Rosano, C., Leoni, A., Ioan, Aiello, C., Croce, M., Andreani, A., Rambaldi, M., Russo, P., Chiarini, A., and Spinelli, D. Inhibition of MDR1 activity and induction of apoptosis by analogues of nifedipine and diltiazem: an in vitro analysis. Invest. New Drug, in press, 2009.

\section{SWEETNESS AND LIGHT: CONTINUOUS GLUCOSE SENSING AND REAL TIME ENZYME ASSAYS USING BORONIC ACID APPENDED VIOLOGENS}

\section{Bakthan Singaram \\ Department of Chemistry and Biochemistry, University of California at Santa Cruz}

Carbohydrates and their derivatives, including saccharides, phosphosugars, and nucleotides, are ubiquitous metabolites in every organism. Sensitive probes for monitoring the presence of these metabolites provide researchers a powerful tool to elucidate biological processes. Our group has extensively developed fluorescent probes for metabolites including glucose, phosphosugars, and nucleotides. We have developed a two-component optical probe with a modular receptor scaffold. This small molecule probe is water-soluble, and operates in the blue-green region of the spectrum. Saccharide recognition in our probe system is achieved with a boronic acids appended viologen that serves as an analyte responsive fluorescence quencher. We used an anionic dye which forms a weakly fluorescent complex with the cationic viologen receptor. At and near physiological $\mathrm{pH}$, saccharide binding by the receptor results in a partial charge neutralization of the viologen. This produces an increase in the fluorescent signal dependent on glucose concentration. Incorporating the probe into a hydrogel polymer allowed for continuous monitoring of glucose concentrations in the physiological range. In another application, an array of probes with differential selectivity was used to discriminate important carbohydrate metabolites in water in multiwell plates and to assay enzymes involved in glycolysis.

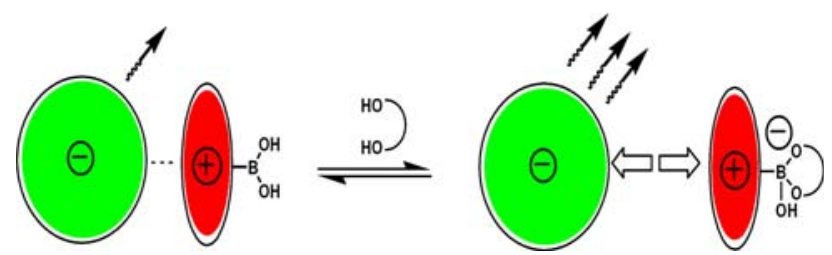

\section{5-DEOXYSPERGUALIN PRIMARILY TARGETS THE TRAFFICKING OF APICOPLAST PROTEINS IN PLASMODIUM FALCIPARUM}

T. N. C. Ramya, ${ }^{1}$ Avadhesha Surolia, ${ }^{1,2}$ Namita Surolia ${ }^{3}$

${ }^{1}$ Molecular Biophysics Unit, Indian Institute of Science, Bangalore 560 012, India; ${ }^{2}$ National Institute of Immunology, Aruna Asaf Ali Marg, New Delhi 110 006, India; ${ }^{3}$ Jawaharlal Nehru Centre for Advanced Scientific Research, Bangalore 560064, India 
15-Deoxyspergualin (DSG) has tumoricidal, immunosuppressive, and antimalarial properties. However, the mechanism of its antimalarial action remains obscure as DSG inhibits a diverse array of cellular processes ranging from a decrease in cellular cytochrome $c$ oxidase activity to depletion of polyamines. To this end, we investigated its effect on Plasmodium falciparum protein synthesis, polyamine biosynthesis, and transport. DSG abrogated protein synthesis in P. falciparum by Hsp70 sequestration and subsequent phosphorylation of the eukaryotic initiation factor eIF2 $\alpha$. However, DSG invoked inhibition of protein synthesis as well as polyamine biosynthesis and/or its transport only at $\sim 1000$-fold higher levels than the submicromolar concentrations at which it was effective as an antimalarial agent. Subsequent experiments demonstrate that DSG specifically disrupts the trafficking of nuclear-encoded apicoplast-targeted (NEAT) proteins to the apicoplast. To our knowledge, this is the first report of delayed death resulting from the inhibition of NEAT protein trafficking by a small molecule. These studies also provide a small molecule to dissect the targeting of nuclearly encoded proteins to apicoplast. Our study not only identifies the primary target of DSG in the malaria parasite, but also uncovers a novel and extremely potent inhibition of a hitherto unexplored apicoplast function.

\section{References}

1. Ramya, T. N. C., et al. J. Biol. Chem., 2007, 282, 6388.

2. Ramya, T. N. C., et al. Biochem. J., 2007, 401, 411.

3. Ramya, T. N. C., et al. Biochem. Biophys. Res. Commun., 2006, 348, 585.

4. Ramya, T. N. C., et al. Biochem. Biophys. Res. Commun., 2006, 348, 579.

\section{MEDICINAL CHEMISTRY: AN EVER EVOLVING DISCIPLINE}

\section{Henk Timmerman}

\section{VU University Amsterdam, The Netherlands}

Medicinal chemistry may be defined as the art to design-and subsequently to synthesise and pharmacologically characterise-on basis of information on structure-property relationships new compounds which should have the right pharmacological and toxicological profile for being suitable as active ingredient in medicinal products.

For obvious reasons, medicinal chemistry could only emerge when organic synthesis became possible; that was around 1855. Until than medicinal products were derived either from biological sources (mainly plants) or metal oxides or salts. The first class contained mainly inactive or only weakly active preparations, the second could be described as especially toxic products. When synthetic medicines were introduced, scientists realized that the chemical properties should be seen as also responsible for their biological effects; structure-activity relationships were already in the 1880 s studied! There was an early euphoria and some investigators expected that soon "medicines could be designed (!!) for any disease." That was before 1900 .

Things developed in a much different way. It was organic chemistry which determined for a long period the progress in medicinal chemistry. Organic chemists synthesised new derivatives which were accessible and pharmacologists searched for useful properties by screening procedures in vivo. Finding new useful compounds was a matter of trial and error and especially luck. Around 1935, the famous pharmacologist Clark sighed, "we have studied structure-activity relationships so intensively that we have a fair knowledge about the extend of our ignorance." The reasons for the failures were manifold, but especially the absence of useful parameters for biological activities made it impossible to derive at useful insights into the relationships between chemical structure and biological property of organic molecules.

When in the 1960s, pharmacology changed into in vitro methods and molecular pharmacology was introduced pharmacology (better pharmacological parameters) started to become responsible for progress in medicinal chemistry; so-called selective compounds became attractive. When somewhat later in time computers became available for complex calculations, a boost in the studies structure-activity 
relationships could be observed. QSAR became a trendy approach and again scientist predicted that it would become relatively easy to design new medicines.

The results of applying the new methodologies were disappointing. The reason was a very intrinsic problem when trying to arrive at new medicines. A medicine cannot be described by one single property. Of course, an active ingredient of a medicine should have a certain property - such as a stimulatory or a blocking effect for a given receptor, but it should also have certain pharmacokinetic properties, other activities should be absent (side effects) and the toxicity profile should at least guarantee a good therapeutic window. Currently, it is more or less possible to design compounds having a predicted property, but that is not sufficient for making useful medicines.

During more recent years, it has been the introduction of molecular biology, the advancement in analytical technologies, the emerging of systems biology, the availability of extremely powerful computers which determine the enormous progress in the possibility to derive at very interesting compounds, A major hurdle remains, however, the complexity of the profile of any compound for making it useful for medicinal applications. This truly intrinsic problem is a very tough one and one might therefore have some doubts whether it will ever be possible to design a new medicine.

In this presentation, historical aspects will be presented, together with a personal opinion about coming developments. An essential characteristic of medicinal chemistry will receive special attention; the field can only flourish an approach in which several disciplines are integrated. The meaning of this conclusion for teaching and training medicinal chemistry will be emphasized as well.

\title{
SYNTHESIS AND/OR REACTIVITY OF NOVEL PYRROLE, INDOLE, 1,2- BENZISOXAZOLE, PHTHALAZINE, XANTHONE, AND NAPHTHALEN- 2(1H)-ONE DERIVATIVES OF POTENTIAL PHARMACOLOGICAL INTEREST
}

\author{
Chrysanthi Dolka, ${ }^{1}$ Virginia Dimaki, ${ }^{1}$ Petros G. Tsoungas, ${ }^{2}$ George Varvounis ${ }^{3}$ \\ ${ }^{1}$ Department of Chemistry, Section of Organic Chemistry and Biochemistry, University of Ioannina, \\ 45110 Ioannina, Greece; ${ }^{2}$ Department of Research and Technology, Ministry of Development, \\ 14-18 Messogion Ave., Athens 115 10, Greece
}

Heterocycles are most prominently characterized as compounds of biological interest. ${ }^{1}$ Through the last years anti-HIV research has been focused in molecules such as pyrrolyl(aryl or lindolyl)sulfones and pyrrolylbenzothiadiazepines with reverse transcriptase inhibiting properties. 1,2-Benzisoxazoles have been recently investigated as inhibitors of $\mathrm{LTB}_{4}$ binding to human neutrophiles, affinity ligands for serotonergic and dopaminergic receptors, selective inhibitors of acetylcholinesterase or for atypical antipsychotic activity. Our continuous interest in phthalazines focuses on their use in the synthesis of semi-mimetics of angiotensin II and oxytocin inhibitors or DNA intercalators. Xanthone is a common structure in Nature. Many of its derivatives bearing methyl, hydroxy, methoxy, or phenyl groups, or those possessing complex polycyclic frameworks, have been isolated from 20 families of higher plants, fungi, and lichens. It is also found in many natural products or other molecules exhibiting a broad spectrum of pharmacological activity. Naphthalen-2(1H)-ones are an important class of pharmacologically active compounds. 1-Hydroxy-1,6-dimethylnaphthalen-2(1H)-ones belong to a group of phytoalexines, produced by the cotton plant Gossypium hirsutum when infected by bacteria. One member exhibits in vitro chemotactic activity toward human polymorphonuclear leukocytes. Several non-natural compounds are inhibitors of HIV-1 reverse transcriptase, genotype 1 hepatitis $\mathrm{C}$ virus (HCV) polymerase, and prolyl hydroxylase activities.

In this lecture, the synthesis of novel pyrrole, indole, pyrrolobenzodiazepinedione, 1,2-benzisoxazole, phthalazine, and naphthalene-2(1H)-ones derivatives will be described. Furthermore, the dimethyl ketal of xanthone will be shown to undergo functionalization with a synthetically useful degree of regioselectivity, using a lithiation protocol. 
<smiles></smiles>

\title{
Reference
}

1. A. R. Katritzky, C. W. Rees, E. F. V. Scriven (Eds). Comprehensive Heterocyclic Chemistry II; Pergamon: Oxford, 1996.

\section{IRON NANOMINERALIZATION IN AN AGED BLOOD PROTEIN: IMPLICATIONS IN DISEASE BIOLOGY}

\author{
Sandeep Verma \\ Department of Chemistry, IIT Kanpur, India
}

Life exists now in an oxidizing environment, and extracellular iron is largely present as Fe(III) rather than $\mathrm{Fe}(\mathrm{II})$, as the former species are acidic and readily form hydroxo and oxo species in aqueous environment. Iron biomineralization is a natural biological process: for example, iron is stored in ferritin as a form of ferrihydrite, and magnetotactic bacteria use magnetite particles as navigational aids. On the other hand, uncontrolled mineralization in biological systems can be deleterious and is thought to be involved in the pathogenesis of various neurodegenerative diseases. We recently reported that human transferrin readily forms protein fibrils and this aging process affords periodic iron nanomineralization along the length of the fibrils. ${ }^{1}$ It is possible such processes may contribute to abnormal accumulation of iron in the brain, which has been implicated a potential debilitating role in neurodegenerative diseases such as Parkinson's, Huntington's, and Alzheimer's. We will also elaborate recent results on this issue, which may unravel molecular understanding of iron deposition leading to design of agents that disrupt human transferrin aggregation.

\section{Reference}

1. Ghosh et al. Periodic iron nanomineralization in human serum transferrin fibrils. Angew. Chem., Int. Ed. 2008, 47, 2217-2221.

\section{QSAR IN DRUG RESEARCH AND IN REGULATORY PROCESSES}

\section{Marjan Vračko}

Kemijski Inštitut/National institute of Chemistry, Hajdrihova 19, 1000 Ljubljana, Slovenia. Tel.: +386-1-4760315, fax: +386-1-4760300, e-mail: marjan.vracko@ki.si 
The QSAR paradigm grounds on assumption that the structure determines the biological properties of a molecule. During the last decades, the QSAR faces strong development due the accessibility of chemical information. The QSAR became well established in two areas: in drug research and in assessments of properties used for regulatory purposes. The background mathematical technics and tools are basically the same; however, the models developed for drug research and for regulatory purposes meet different requirements.

In drug research, the QSAR is used for optimizing of structures respecting the bioactivity of a drug candidate. In the first stage of drug discovery, it is used for searching of lead compounds where a large quantity of data from high-throughput screening must be analyzed. In the later stage, the QSAR is used to evaluate the ADME properties for (still) large number of candidates. Generally, in the searching of new active compounds the fals positives are points of concern (synthesis and testing of a new fals positive is expensive).

QSAR is used in regulatory processes for evaluation of physico-chemical, eco-toxicological, and toxicological properties of chemicals. The models used for regulatory purposes should be developed in spirit of OECD principles for validation of QSAR models, which ensure their transparency and reproducibility. In the presentation, we discuss the role of QSAR methods in European Chemical Legislation (REACH). Generally, for regulatory purposes usually the conservative evaluation of predictions is considered (fals negatives are points of concern).

In the presentation, we present more details about strategies and methods in both areas and show some examples. A discussion will be rised where both areas can interact.

\title{
AN EFFICIENT PRACTICAL SYNTHESIS OF THIO-BISPHOSPHONIC ACIDS FOR THE TREATMENT OF ARTHRITIS, BASED ON THE CHEMISTRY OF DISUFIDES
}

\author{
Wafaa M. Abdou, Abeer A. Shaddy \\ Chemical Industries Division, National Research Centre, Dokki, Cairo, Egypt. e-mail: wabdou@link.net
}

The bisphosphonates (BPs), in particular, the nitrogen containing analogs, have been demonstrated to be potent inhibitors of bone resorption, and highly selective bone targeting agents. Lately, it has been reported the utility of sulfur containing bisphosphonic acids $\left(\operatorname{HSEDP}^{\mathrm{R}}\right)$ in therapy of arthritis, particularly rheumatoid. These results have led us to attempt to utilize the high bone/joint specificity of this class of compounds together with other chemical moieties with potential anticatabolic pharmacology in the design of specialized antiarthritic agents.<smiles>O=C(O)C(CS)P(=O)([O-])O</smiles>

HSEDP

The S- and N-containing bisphosphonic acids have therefore examined as chondro-protective therapy for the treatment of arthritis. Several of these have demonstrated potency both in vitro and in vivo. The newly synthesized compounds all contain a latent or a free thiol group, which may bind to the zinc atom in the active site of the matrix metalloproteases.

The most interesting series utilizes a rigid N-heterocycle group with a bisphosphonic acid as a potential "bone hook" and a pendant thiol chain present for interaction with the enzyme systems. The synthesis of these compounds was accomplished from the application of cyclic-, acyclic cis-disulfides, and some arylidenes and halo-substrates. Hydrolysis of the resulting BPs affords the bisphosphonic acid. 
The in vivo activity of some of these bisphosphonic acids in the rat adjuvant model of arthritis will also be discussed.

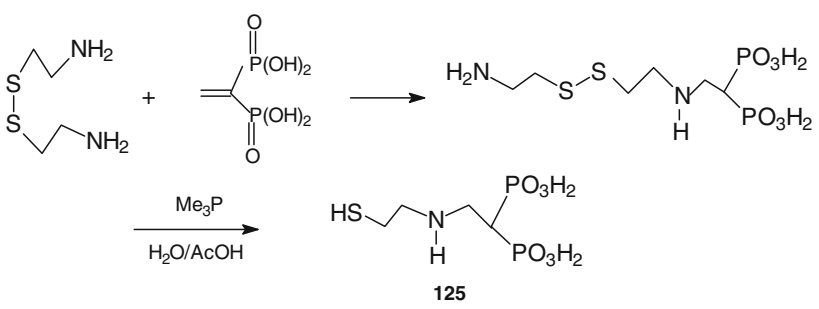

\title{
References
}

1. Abdou, W. M., Shaddy, A. M., Consideration, Arkivoc, 2008, 9, 143-182.

2. Abdou, W. M., Ganoub, N. F., Gironikaki, A., Sabry, E., Eur. J. Med. Chem. 2008, 43, 1015-1024.

\section{TARGETING THE HIV-1 TRANSCRIPTION COMPLEX: A CLINICAL AND TRANSLATIONAL ENTERPRISE}

\author{
Vanessa Pirrone, ${ }^{1,2}$ Shendra Passic, ${ }^{1,2}$ Jeffrey Jacobson, ${ }^{1,2,3}$ Sandhya Kortagere, ${ }^{1}$ Nirmala Rajagopalan, ${ }^{4}$ \\ J. B. Suchitra, ${ }^{4}$ Zafar Khan, ${ }^{1,2}$ Michael R. Nonnemacher, ${ }^{1,2}$ Brian Wigdahl $^{1,2}$ \\ ${ }^{1}$ Department of Microbiology \& Immunology, ${ }^{2}$ Institute for Molecular Medicine \& Infectious Disease, \\ ${ }^{3}$ Division of Infectious Disease, HIV Medicine, Department of Medicine, Drexel University College of \\ Medicine, Philadelphia, PA, USA; ${ }^{4}$ Freedom Foundation, Bangalore, India
}

HIV-1 long terminal repeat (LTR) serves a number of critical functions in viral replication, one of the most prominent of which involves regulating the transcriptional activity of the HIV-1 provirus. The HIV1 LTR ( 630-660 bp) contains several cis-acting elements, which specifically bind host transcription factors and thereby modulate promoter activity. We have previously demonstrated with clinical material obtained in the pre-HAART era that sequence variation at HIV-1 LTR C/EBP site I and Sp site III, in peripheral blood (PB)-derived LTRs, revealed sequence configurations that were found to increase in prevalence with disease severity and correlate with HIV-associated dementia (HAD). In contrast, LTR $\mathrm{NF}-\kappa \mathrm{B}$ sites I and II were highly conserved regardless of disease severity. Additional information has also suggested that the viral trans-activator protein Tat and viral protein $\mathrm{R}(\mathrm{Vpr})$ may play integral roles in regulating viral gene expression during the course of CNS disease and HIV disease in the peripheral blood and lymphoid tissues based on highly specific interactions with sequences within and adjacent to the LTR core/enhancer region as well as proteins involved in the basal, stimulated, and activated transcription complex. To explore the impact of genetic variation within the HIV-1 subtype B LTR, Tat, and Vpr sequences within the context of cross-population and longitudinal clinical studies in the era of combination anti-retroviral therapy (ART), we have now enrolled more than 400 patients in the DREXEL MEDICINE HIV/AIDS Genetic Analysis Cohort with approximately 1,100 remaining to be enrolled in this continuously expanding clinical cohort. Utilizing a peripheral blood mononuclear cell (PBMC) PCR product-based high throughput sequencing approach, we have identified a series single and co-selected nucleotide polymorphisms (SNP and csSNP, respectively) in the viral LTR within 12 transcription factorbinding sites that correlate with late stage HIV-1 disease. The SNP and csSNP identified based on their increased prevalence in late-stage disease are being examined with respect to specific signatures in their corresponding Env and Tat sequences. We are also exploring the functional properties of the HIV-1 LTR and Tat protein with respect to genome activation in late stage HIV-1 disease. Studies are also underway to explore the functional properties of the HIV-1 subtype C LTR and Tat protein regarding viral genome activation. 


\title{
ANTIMICROBIAL ACTIVITY AND STRUCTURE-ACTIVITY RELATIONSHIPS OF SOME SYNTHESIZED BENZAZOLES AND THEIR POSSIBLE METABOLITES
}

\author{
Ismail Yalcin, Esin Aki, Ilkay Yildiz, Ozlem Temiz-Arpaci
}

Ankara University, Faculty of Pharmacy, Pharmaceutical Chemistry Department, Tandogan 06100, Ankara,Turkey.e-mail: yalcin@ankara.edu.tr

The dramatically rising prevalence of multidrug-resistant microbial infections in the past few decades has become a serious health care problem. ${ }^{1,2}$ In order to prevent this serious medical problem, the elaboration of the new types of the previously known drugs is a very actual task.

Various fused heterocyclic compounds and different amides structures have been the aim of many researches as an important class of antimicrobial agents for many years; because of they constitute substantial chemotherapeutic activities. In the last few years, we reported some derivatives of benzazoles such as benzoxazoles, benzimidazoles, benzothiazoles, and the possible metabolites of benzoxazoles possessing amide structures, which are exhibited antibacterial and antifungal activities as well as showing effects on some multidrug resistance strains. ${ }^{3,4}$

The antimicrobial activity results and the predictions for the lead optimization observed from the QSAR analysis and common-features hypotheses that are generated by using Catalyst 4.9 for finding the chemical features among the sets of synthesized fused heterocylic compounds and the possible metabolites of benzoxazoles holding amide structures given in the figure below will be discussed.
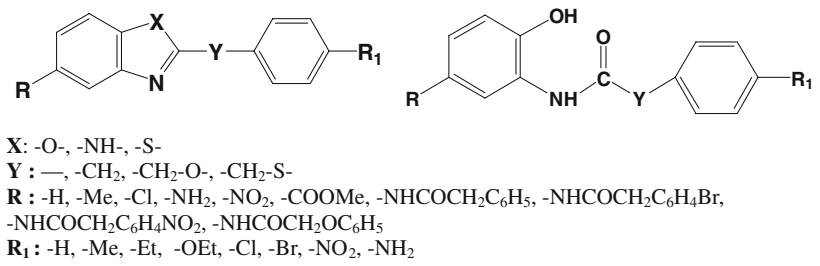

\section{References}

1. Lee, V., Hecker, S., J. Med. Chem. 1999, 19, 521.

2. Livermore, D., Int. J. Antimicrob. Agents 2000, 16, S3

3. Arisoy, M., Temiz-Arpaci, O., Yildiz, I., Kaynak-Onurdag, F., Aki, E., Yalcin, I., Abbasoglu, U., SAR and QSAR in Environmental Research, 2008, 19(5-6), 589.

4. Yildiz, I., Ertan, T., Bolelli, K., Temiz-Arpaci, O., Yalcin, I., and Aki, E., SAR and QSAR in Environmental Research, 2008, 19, 101. 